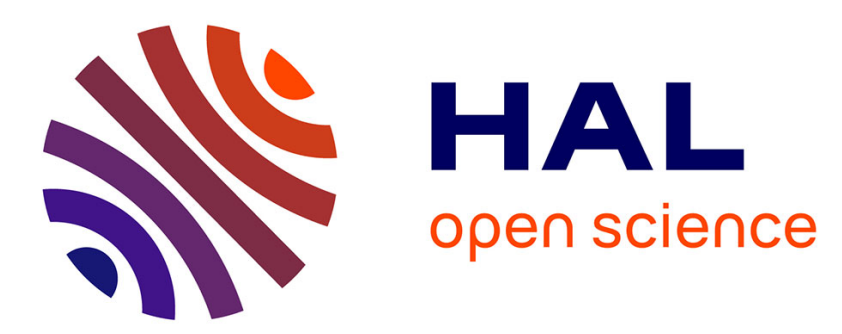

\title{
Erosive flood events on the surface of Mars: application to Mangala and Athabasca Valles
}

Alistair Simon Bargery, Lionel Wilson

\section{To cite this version:}

Alistair Simon Bargery, Lionel Wilson. Erosive flood events on the surface of Mars: application to Mangala and Athabasca Valles. Icarus, 2011, 212 (2), pp.520. 10.1016/j.icarus.2011.01.001 . hal00734590

\section{HAL Id: hal-00734590 \\ https://hal.science/hal-00734590}

Submitted on 24 Sep 2012

HAL is a multi-disciplinary open access archive for the deposit and dissemination of scientific research documents, whether they are published or not. The documents may come from teaching and research institutions in France or abroad, or from public or private research centers.
L'archive ouverte pluridisciplinaire HAL, est destinée au dépôt et à la diffusion de documents scientifiques de niveau recherche, publiés ou non, émanant des établissements d'enseignement et de recherche français ou étrangers, des laboratoires publics ou privés. 


\section{Accepted Manuscript}

Erosive flood events on the surface of Mars: application to Mangala and Athabasca Valles

Alistair Simon Bargery, Lionel Wilson

PII:

S0019-1035(11)00002-9

DOI:

10.1016/j.icarus.2011.01.001

Reference:

YICAR 9680

To appear in:

Icarus

Received Date: $\quad 20$ June 2010

Revised Date: $\quad 28$ December 2010

Accepted Date: $\quad 3$ January 2011

Please cite this article as: Bargery, A.S., Wilson, L., Erosive flood events on the surface of Mars: application to Mangala and Athabasca Valles, Icarus (2011), doi: 10.1016/j.icarus.2011.01.001

This is a PDF file of an unedited manuscript that has been accepted for publication. As a service to our customers we are providing this early version of the manuscript. The manuscript will undergo copyediting, typesetting, and review of the resulting proof before it is published in its final form. Please note that during the production process errors may be discovered which could affect the content, and all legal disclaimers that apply to the journal pertain. 
Erosive flood events on the surface of Mars: application to Mangala and

\section{Athabasca Valles}

Alistair Simon Bargery and Lionel Wilson

Lancaster Environment Centre, Lancaster University, Lancaster, LA1 4YQ, UK

Number of manuscript pages: 62

Number of tables: $1(+1$ notation table)

Number of figures: 17 
Proposed Running Head: Erosive floods on Mars

Editorial correspondence to:

Dr. Alistair Bargery

Lancaster Environment Centre

Lancaster University

Lancaster LA1 4YQ, UK

phone: +44-1524-593889

fax: +44-1524-510217

e-mail: a.bargery@lancaster.ac.uk 


\begin{abstract}
We address key factors involved in determining water flow conditions in outflow channels on Mars, including the temperature of the sub-surface water being released and the environmental conditions of low temperature, low atmospheric pressure, and low acceleration due to gravity. We suggest how some of the assumptions made in previous work may be improved. Our model considers the thermodynamic effects of simultaneous evaporation and freezing of water, and fluid dynamical processes including changes in flow rheology caused by assimilation of cold rock and ice eroded at the channel bed, and ice crystal growth due to water freezing. We model how far initially turbulent water could flow in a channel before it erodes and entrains enough material to become laminar, and subsequently ceases to erode the bed. An ice raft will begin to form on the flood while transition occurs between turbulent and laminar flow. Estimates are given for water transit times, $\sim 17$ to $\sim 19$ hours, initial water depths, 50 to $62 \mathrm{~m}$, and average flow speeds, 5 to $12 \mathrm{~m} \mathrm{~s}^{-1}$, in the Mangala and Athabasca Valles. We show that these two outflow channels, and by implication others like them, could plausibly have been formed in single water release events. Resulting mean erosion rates are approximately $0.7 \mathrm{~mm} \mathrm{~s}^{-1}$, a factor of three greater than previous estimates based on combinations of estimates of flood duration and required water volumes. This is explained by the consideration of the effects of eroded ice and the physics of thermal erosion in the present study.
\end{abstract}

Keywords: Geological processes; Mars, surface; Outflow channels; Water 


\section{Introduction}

Studies of the formation of water outflow channels on Mars have addressed mechanisms for fracturing the cryosphere of Mars (Carr, 1979; Max and Clifford, 2001; Chapman and Tanaka, 2002; Head and Wilson, 2002; Chapman et al., 2003; Rodriguez et al., 2003, 2005; Leask et al., 2006a; Burr et al., 2009), discharging water through the resulting fractures from subsurface aquifers (Rice et al., 2002; Head et al., 2003; Wilson and Head, 2003; Manga, 2004; Ghatan et al., 2005; Hanna and Phillips, 2006; Leask et al., 2006b; Andrews-Hanna and Phillips, 2007; Bargery and Wilson, 2010), and various aspects of the mechanics of the resulting fluid flows on the surface (Baker and Milton, 1974; Baker, 1979; Komar, 1979; Wallace and Sagan, 1979; Baker, 1982; Carr, 1983; Wilson et al., 2004; Kleinhans, 2005; Wilson et al., 2009). Such models can be constrained by geomorphological data and analyses (Gupta et al., 2007; Burr et al., 2009; Pacifici et al., 2009; Warner et al., 2009).

The contribution presented here is a more advanced model of the fluid dynamics of large-scale fluid flow on Mars, with application to two selected outflow channels. There is a need for such elaborations on models due to two main concerns, as follows. Firstly, previous models of the dynamics of water flow on the surface of Mars have assumed that an ice cover forms initially as a result of rapid cooling and have begun their analyses of the energy balance from this starting point (Wallace and Sagan, 1979; Carr, 1983). Little attention has been paid to the behaviour of liquid water before an ice cover forms, although Heldmann et al. (2005) formulated a model to describe liquid water flow in the Martian valley networks; however these are on a far smaller scale than the outflow channels. Secondly, and perhaps more importantly, there is a discrepancy between model results, wherein some have very short hydrographs (e.g., Manga, 2004), implying that multiple floods are required to erode observed channels, while other modelling (e.g., Burr et al., 2002) effectively assumes 
that observed channels were formed from single flood events. A recent geomorphological study (Pacifici et al., 2009) of Ares Vallis concluded that the channel has experienced multiple flood events; however, more studies, both geomorphological and modelling, are required to know if such a conclusion could be drawn for all the other outflow channels, and whether this exhibition of evidence for multiple floods is supported by modelling. Whether or not outflow channels experienced multiple flooding, or whether the number of flood events for a particular channel depends on specific factors governing fluid flow that may vary from one channel to another, are questions we focus on here. In order to answer these questions, we consider the key issues of the distance to which a flood can advance before the water speed becomes negligible and the time required for this to occur. If this time is much less than the duration of water release from the sub-surface source then there may be multiple phases of flow at the more distal locations and channel formation may be a complex process, as reviewed by Burr et al. (2009). A hypothesis tested in this paper is that Athabasca and Mangala Valles outflow channels could have been eroded at a rapid rate by a single, high-discharge flood event, with only liquid water being initially released. In order to test this hypothesis, we examine the range of possible conditions under which water can flow in a channel to distances equivalent to the lengths of the outflow channels. We conclude by discussing the model implications, especially those for erosion rates and discharges in outflow channels.

\section{Model overview}

Our model draws on and extends earlier work by Wallace and Sagan (1979), Baker (1982), and Carr (1983), while incorporating the recent conceptual model of Wilson et al. (2009), who reviewed the current knowledge of outflow channel flow and discussed the governing factors of fluid flow. The model is purely physical and involves no chemical changes. It is spatially-varying but not strictly time-varying in 
relation to the development of a flood. Rather, it follows the progress of a given batch of water from the source region to the distal end of a channel. We assume incompressible flow. The distance travelled and the speed of the flow control the time taken to reach the end of the channel. Factors included in the model are cooling at the surface, assimilation of ice and rock fragments from its eroded bed, and formation of ice crystals which, together with the sediment load, produce profound changes in its rheology.

Fig. 1 shows the stages we envisage to occur in a channel flow on Mars, each distinguished by the dominance of particular heat and mass exchange processes as well as changes in flow rheology and transport mode of solids. We compare the model of Carr (1983) with the one developed here. Carr's model only considered the processes involved after formation of an ice cover (Fig. 1, stage 4); here we also address the earlier stages of an uncovered water flow (Fig. 1, stages 1-3). For all plausible outflow channel flows, the depth and speed of the water will cause the motion to be turbulent so that heat is transferred through most of the fluid by convection during these first three stages of flow. We now outline the definitions of the four proposed stages.

\subsection{Stage 1}

On Mars, when liquid water becomes exposed to the atmosphere, it will start to evaporate because the atmospheric pressure is less than the vapour pressure of liquid water at almost all temperatures above the freezing point. The rate of loss of mass by evaporation will depend on the water temperature and its salt content. Removal of mass is accompanied by the removal of the latent heat of vaporisation and so the water begins to cool. In stage 1, the water remains turbulent and cools from its release temperature to the freezing point while eroding the substrate of cryosphere rock and ice. Any eroded ice is at a lower temperature than the water, and is therefore melted, 
thereby adding to the liquid water content of the flow. Even though the surface of Mars is below freezing and eroded ice is incorporated at the bottom of the flow, heat loss and cooling is considered to occur from the surface only, so that cooling of the water due to heat transfer to eroded material contributes to cooling at the surface (see section 3.6).

At some point during this cooling the freezing point of the water is reached, initiating stage 2 .

\subsection{Stage 2}

For the range of atmospheric pressures experienced on the Martian surface, liquid water at a temperature just above its boiling point is also just above its freezing point (e.g., Bargery et al., 2010). In other words, liquid water is not generally stable on the surface of Mars except under a very limited P-T range, so that water released as a liquid is out of equilibrium, and cools by boiling until the liquid temperature reaches the freezing point of water. Hence, boiling ceases once the bulk flow temperature is at the freezing point because the water vapour pressure of water at the triple point, 611 $\mathrm{Pa}$, is barely greater than the atmospheric pressure at most locations on Mars. However, latent heat continues to be removed from the water through both evaporation and warming the entrained ice and rock to the ice melting point, as in stage 1. Ice crystals start to form and accumulate within the turbulent flow. Ice entrained from the cryosphere is no longer melted by contact with the liquid water and the bulk temperature remains constant at $273.15 \mathrm{~K}$.

\subsection{Stage 3}

Ice crystal formation continues slowly because the heat loss rate from the fluid by evaporation is due now to a very small difference between the vapour pressure of water at the triple point and the atmospheric pressure. The increasing load of solids, 


\section{ACCEPTED MANUSCRIPT}

both rock fragments and ice crystals, eventually begins to influence the rheology of the bulk flow by increasing the viscosity and causing a yield strength to develop. The increasing fluid viscosity causes a decrease in the Reynolds number (the dimensionless ratio of inertial to viscous forces that controls the flow regime). At the same time the increasing yield strength increases the threshold Reynolds number above which the flow is turbulent, and the combined result is a major reduction in turbulence so that the majority of sediment within the flow changes from washload to bedload, thereby initiating stage 3 .

\subsection{Stage 4}

In stage 4 , the shear stress at the boundary between the flow and the ground decreases rapidly as turbulence is damped out and the flow regime transitions to laminar. As the flow energy available for transportation decreases, deposition of all but the finest silicate sediment must begin. An ice raft will also begin to form as the buoyant rise velocity of ice crystals exceeds the turbulent velocity. Ice will form at the surface due the loss of latent heat of evaporation (and removal of energetic water molecules due to boiling whilst the water temperature is above the freezing point) from the surface of the flow. However, they will not remain at the surface while the flow is turbulent, but will be dragged downwards due to the velocity of the water column, with eddies and other fluid movements exerting forces on the ice crystals. Only when the solids volume fraction within the flow is great enough to increase the viscosity and reduce flow turbulence to the laminar regime will the ice crystals be able to float to the surface. In reality, it is likely that ice crystals will also form directly within the water due to the heat lost due to warming cold material eroded from the bed, and these ice crystals will also move with the flow. The erosive power of a laminar flow is much less than that of a turbulent flow, mostly because of the dependence of the erosion rate on the Reynolds number (see section 3.1; Carr, 1974; 
Morgan et al., 1998), and we assume in the model that erosion will cease once the flow becomes laminar (in reality, erosion will continue but will become negligible). The rheology of the slurry beneath the ice raft is by now extremely non-Newtonian, and once there is no liquid water left in the flow, it can be considered as a rock glacier rather than a flood of liquid water. Further heat loss will occur through sublimation.

\subsection{Model parameters}

The parameters of the model (see Notation Table) can be classified into four groups: (a) gross channel morphological characteristics; (b) physical property constants; (c) user-defined independent variables, i.e., model inputs; and (d) dependent variables, i.e., model outputs. The classification of each and every parameter is shown in the last column of the notation table.

\subsubsection{Group (a) parameters}

Group (a) parameters have known values from observational data, and are specific to each channel. Table 1 lists measured or inferred gross characteristics of two Amazonian outflow channels, including channel width and depth, channel length (the distance oyer which the channel is discernible topographically from the surrounding area with reasonable confidence), and the slopes of both the region surrounding the channel and the channel floor. These parameters are specific to each channel, and therefore may be regarded as independent variables.

These are post-flood parameters, so that we assume that the channel shape and dimensions controlled the fluid dynamics. Pre-flood parameters cannot be used in a model such as ours, because initially the flow would not be channelised, but rather would be a sheet-like flow, and some of the fluid dynamical equations would be inapplicable. We therefore assume that the flow erodes the ground rapidly near the source to produce a channel that acts to 'self-confine' the flood of water. The 
morphology of the pre-flood topography is not always clear. The best one can do is to use post-flood channel dimensions.

\subsubsection{Group (b) parameters}

Group (b) parameters, e.g., the freezing point of water, are constant within and for the duration of a particular run of the program, and also remain constant between applications to the various outflow channels. The initial water temperature is set as $313 \mathrm{~K}$, as a reasonable estimate of the temperature of groundwater released from subsurface aquifers on Mars (Bargery and Wilson, 2010). The flow capacity, defined as the maximum possible volume fraction of solids capable of being transported by a flow, is discussed later (Section 3.2), but is set to 1 in the model.

\subsubsection{Group (c) parameters}

Group (c) parameters, model inputs, are initial water depth at the proximal end of the channel, and the parameters $D_{50}$, and $D_{84}$. The values of these factors will vary between channels and accurate values for them are unknown, so we test a range of plausible values for each. The model inputs are varied to find the best fit between the calculated distance that water can travel before the erosion rate decreases to zero and the observed length of each channel as given in Table 1. In order to assess the time that a given batch of released water would take to reach the end of the channel, the model is used to calculate the water speed as a function of distance and time from the water release point.

\subsubsection{Group $(d)$ parameters}

Group (d) parameters, e.g., erosion rate, water depth and speed, change with distance from the source in a way determined by the constituent equations of the model and the initial water release conditions. Hence these parameters could be 
considered as model outputs and therefore they vary depending on the channel for which a flood is being modelled.

\section{Model formulation}

We now specify mathematically the physical processes involved at various stages in the development of a water flood on Mars. The relative importance of these processes changes along the flow as shown in Fig. 1, stages 1-3. Stage 4 is modelled only partially, assuming that no ice cover forms even when the flow becomes laminar. This is unrealistic, and this issue will be addressed in a future paper. A full treatment is not needed here because modelling of stages 1-3 can give the required predictions of flow characteristics while the flood is turbulent and continues to erode its base.

\subsection{Bed erosion rate}

The bed erosion rate is a key factor determining the conditions within the outflow channels. However, there are no data for Martian flood erosion rates, since flooding has never been observed. Erosion rates for floods on Earth on the scale of the Martian floods, e.g. the Channeled Scablands (Baker and Milton, 1974), are also available only as indirect estimates, again because of a lack of direct observation. The nearest approximation to the relevant conditions on Earth probably occurs during jokulhlaups, in which erosion depths of $\sim 5 \mathrm{~m}$ can occur in 1-2 days (Smith et al., 2002) implying erosion rates of $\sim 0.03 \mathrm{~mm} / \mathrm{s}$. Previous workers have attempted to estimate erosion rates on Mars using the average depths of the outflow channels, $\sim 100 \mathrm{~m}$ (Table 1), and estimates of the durations of the floods that carved the outflow channels, between 1 week and 10 weeks (Komar, 1979), which imply erosion rates of between $0.165 \mathrm{~mm} / \mathrm{s}$ and $0.0165 \mathrm{~mm} / \mathrm{s}$ (Coleman and Dinwiddie, 2005).

On the scale of the outflow channels, there is no quantitative assessment in the literature of how the erosion rate varies with sediment concentration. Neither is there a 
generally accepted and universally applicable relationship between channel flow dynamics and erosion within a bedrock channel (Andrews-Hanna and Phillips, 2007). Most models relate the erosion rate, $e$, to either the stream shear stress on the bed, ${ }^{\tau} 0$, sometimes referred to as the "stream power" (Sklar and Dietrich, 1998), which for turbulent flow is defined by

$$
\tau_{0}=\mu \llbracket \llbracket 21 \square 32 v \llbracket r
$$

where $\mu$ is the viscosity of the flow, $r$ is the hydraulic radius of the channel, defined as the cross-sectional area of the flow divided by the wetted perimeter, 1 and $v$ are constants summing to unity (see Bargery, 2007) which relate to the velocity profile of the flow, and $\bar{u}$ is the mean flow speed. For laminar flow, the relationship does not require such complex coefficients and $\tau_{0}$ can be described simply as $\tau_{0}=2 \mu \bar{u} / r$.

One model of bed erosion rate was developed by Whipple et al. (2000), who argued that the erosion rate is best represented as $e=K_{\tau} \tau_{0^{a_{i}}}$, where $K_{\tau}$ is a dimensional parameter that is poorly constrained and highly dependent upon the mechanism of erosion and the rock type, and $a_{\tau}$ is an exponent dependent upon the erosive process. Considering the physical processes behind the key erosive mechanisms, Whipple et al. (2000) estimated exponent values of $3 / 2,5 / 2$, and 7/2 for plucking, abrasion by suspended load, and cavitation, respectively. Their cavitation model was poorly constrained, and they noted a lack of direct observational evidence for erosion by cavitation within the bedrock channels of their study. Furthermore, Fig. 16.7 in Wilson et al. (2009) shows that the super-critical flow required for cavitation was not likely to have occurred during the outflow channel floods on Mars (most flow conditions yield $F r<1$ ). Due to these uncertainties, we do not consider erosion by cavitation here. It has been argued that erosion by plucking was important for both the Channeled Scablands and the outflow channels (Baker and Milton, 1974; Baker, 1979; 
Baker and Kochel, 1979), suggesting that a shear stress exponent of $3 / 2$ is most representative of erosion in the channels. The streamlined islands observed in some channels (Baker and Milton, 1974) are unlikely to be the result of scouring by suspended load, but rather due to plucking by giant eddies. We note, however, that abrasion by suspended load, or scour, may result in channel-scale features that are morphologically similar to channel-scale features formed from plucking of blocks (Carling et al., 2009).

Since the temperature of liquid water on Mars will at all times exceed the average ground surface temperature, $\theta_{\mathrm{c}}=210 \mathrm{~K}$, by at least $60 \mathrm{~K}$, we need to consider thermal erosion, i.e. the erosion of the cryosphere that forms the bedrock by disaggregation of silicates as interstitial ice is melted. We have modified a treatment of thermal erosion of the frozen banks of periglacial rivers on Earth (Randriamazaoro et al., 2007) for application to Mars, where the ground temperature is much less, using the following analysis. The primary controlling parameters of the erosion rate, $e$, are the Reynolds number, $R e$, and the water temperature, $\theta_{\mathrm{w}}$. The dependence of $e$ on $R e$ is found from the asymptotes of the top right-hand graph of Fig. 4 in Randriamazaoro et al. (2007); taking values from this graph enables one to plot erosion rate against (Re/15900). The dependence of $e$ on $\theta_{\mathrm{w}}$ is found from considering Fig. 4 of Randriamazaoro et al. (2007), and their discussion, as well as the results of a constantrate melting model (Costard et al., 2003), which together imply that $e$ is proportional to $\theta_{\mathrm{w}}$. Finally, after studying the bottom-left graph of Fig. 6 in Randriamazaoro et al. (2007), we find that the erosion rate depends very weakly on the ground surface temperature, with only a $10 \%$ change in the coefficient of proportionality, $\varepsilon$, for a 30 K change in ground temperature. From Fig. 5 in Randriamazaoro et al. (2007) we estimate an asymptote of $\sim 1.3 \times 10^{-5} \mathrm{~m} \mathrm{~s}^{-1}$ for $R e=15900$ and an ice temperature of 265.65 K; however, we require $\theta_{\mathrm{c}}=210 \mathrm{~K}$ so we extrapolate the bottom-right part of 
their Fig. 4 and estimate that another factor of $\sim 1.7$ is required for application to Mars. Hence our estimate of the erosion rate is given by

$$
e=\varepsilon\left(\theta_{\mathrm{w}} / 5\right)(\operatorname{Re} / 15900)^{0.327}
$$

where $\theta_{\mathrm{w}}$ is the flow (i.e., water plus sediment) temperature in ${ }^{\circ} \mathrm{C}, \operatorname{Re}$ is the Reynolds number of the flow, and $\varepsilon=7.9 \times 10^{-6} \mathrm{~m} \mathrm{~s}^{-1}$ for Mars. We assume that thermal and mechanical erosion are the only two erosive mechanisms operating in channel flow on Mars.

\subsection{Flow capacity, sediment grain size, and transport mode}

Kleinhans (2005) provides a thorough and important discussion on the likelihood of outflow channel flows being hyper-concentrated. He shows that the settling velocity is hindered in such flows, and that a certain amount of energy is dissipated in transporting large volume fractions of sediment. His discussion concludes that the concentration of sediment, $\varphi_{\mathrm{w}}$, that can be transported as washload depends on three main factors: the flow capacity, $\varphi_{\max }$, the mean flow velocity, $\bar{u}$, and the settling velocity, $\omega$, leading to his Eq. (53):

$$
\frac{u^{3}}{g h w_{s}}=\frac{\phi_{w}}{\rho_{s} b 1+\alpha_{c}}\left[1-\frac{\phi_{w}}{\phi_{\max }}\right]
$$

where $\rho_{s}$ is the average density of the solids (rock and ice), $\alpha_{c}$ is a constant equal to the ratio $\left(\rho_{\mathrm{r}}+\rho_{\mathrm{i}}-\rho_{\mathrm{w}}\right) /\left(\rho_{\mathrm{r}} \rho_{\mathrm{w}}\right)$, and $b$ is also a constant equal to $\left(1.47 \times 10^{-5} / \alpha_{\mathrm{c}}\right)$. We implement this equation in our model and solve for $\bar{u}$. In doing so, we take account of 
the ice in the flow so that the density $\rho_{\mathrm{s}}$ is the average density of the solids, rather than only the density of the rock.

Since the current model describes the variation of the sediment concentration transported as washload as a function of the flow speed, it is also used to calculate the corresponding settling velocity, $\omega,($ Kleinhans, 2005)

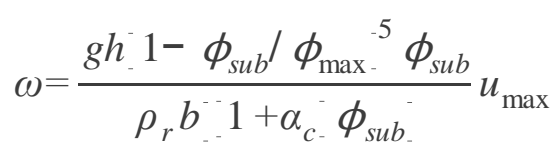

and hence the variation over time of the threshold of the maximum particle diameter $\left(D_{\max }\right)$ that the flow is capable of transporting as washload (in suspension) by the flow, according to

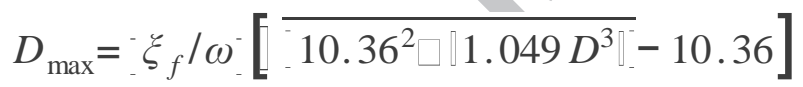

where $D_{*}$ is the Bonnefile number (see van Rijn, 1984). However, since we have no information on the actual grain size distribution, or even on typical sizes of material plucked from the bed, it is not yet possible to model the deposition of grains with dimensions that exceed the maximum particle diameter transported in suspension. Such an elaboration would be an improvement in future models.

The total solid volume fraction cannot exceed the transport capacity of the flow. Therefore, erosion must cease when the capacity is reached, unless deposition occurs. Furthermore, since the volume fraction of ice crystals continues to increase due to freezing of the water, the flow must begin to deposit sediment, at the rate of production of the ice, to maintain the volume fraction of solids equal to or less than the flow capacity. Once the flow has deposited some sediment, it may be expected that space becomes available for renewed erosion; however, the capacity of the flow 
remains constant and any solids lost from the flow as deposited sediment are replaced by more ice forming from freezing of the water. The flow could travel a very long way once erosion stops, because heat loss to eroded material will no longer occur, and heat loss due to evaporation and conduction into the subsurface are very slow processes. Deposition of sediment and ice formation must continue until no water remains in the flow, at which point the flow can be considered as a solid mixture of rock and ice. It will no longer move as a sediment-laden mud flow or river, but will continue to erode its substrate at the very much slower erosion rate of glacial action. However, if water is still being released from the source, then continuity requires that some complex ponding process must occur behind the near-stationary solid; we do not consider that complication here.

Komar (1980) estimated that $40 \%$ solids volume fraction is a plausible upper limit for hyper-concentrated flows, but Kleinhans (2005) argued that it was not possible for flows in Martian channels to become hyper-concentrated at all through erosion alone, without sediment being loaded into the flow by an external agent such as bank collapse. However, the total volume fraction of solids in a Martian flow is equal to the sum of the volume fractions of ice and rock. Wilson et al. (2009) suggest that, because formation of ice crystals in the flow must inevitably occur as heat is extracted, the solids volume fraction can exceed that which would normally be considered as equivalent to the flow capacity for water floods on Earth. We therefore consider the possibility that the flow could be $100 \%$ solid at its distal end. Nevertheless, the fact that we assume that erosion ceases when the flow becomes laminar limits the solids volume fraction in the flow eroding the channel to that at the point of transition between turbulent to laminar flow; Table 1 and the results section give typical solids volume fractions at this transitional point.

\subsection{Flow velocity and friction factors}


In practice all Martian water flows are initially turbulent unless they are shallower than about one meter. A relationship between mean flow speed, $\bar{u}$, and flow hydraulic radius, $r$, comes from the Darcy-Weisbach equation (e.g., Bathurst, 1993; Equation 16.7 in Wilson et al., 2009) for turbulent water flow in a channel, which relates the mean flow speed to other parameters via a friction factor $f_{\mathrm{c}}$, values of which are a function of bed roughness and $r$. Fig. 16.4 in Wilson et al. (2009) illustrates the relationship for various slopes and radii.

The hydraulic radius of the channel, $r$, is a function of the mean width of the channel, $W$, and the mean water depth $h$, as defined by Equation 16.5 in Wilson et al. (2009). If $W$ is much greater than the total flow depth of the water in the channel, $h$, which is true for Martian outflow channels, then

$$
r=\frac{h}{\left.\llbracket 1 \square 2\left[\frac{h}{W}\right]\right]} \approx h
$$

It is unreasonable to assume that any of the Martian channels were ever bankfull (e.g., Andrews-Hanna and Phillips, 2007); maintaining a bank-full condition during bed erosion would require the discharge rate to increase steadily with time throughout each flood. We therefore test the consequences of assuming a range of ratios of initial water depth to observed mean channel depth, $\left(h_{0} / a\right)$, with $h_{0} / a<=1$, where $a$ is the mean depth of the channel. We note that this unavoidably ignores the very earliest phase of channel formation when the pre-flood topography must define the location of the water path that is subsequently subject to erosion.

The key requirement for characterising water flow in channels is to express $f_{\mathrm{c}}$ as a function of the nature of the bed, mainly the bed roughness. There are many empirical field and laboratory data for the friction factor $f_{\mathrm{c}}$ as a function of the nature 
of the channel bed and the flow conditions, which are described in detail elsewhere (Bathurst, 1993; Wilson et al., 2004; Wilson et al., 2009).

To visualise the effect of various values of friction factors, Fig. 2 compares the friction factor as a function of water depth for channel beds dominated by various grain sizes on Mars, following equations 16.8 to 16.14 summarised in Wilson et al. (2009). We note that $f_{\mathrm{c}}$ is a constant for fall and pool channels on Mars, but this is probably not relevant because these features do not occur on the same scale as the outflow channels, which is the scale used in the model to produce Fig. 2. We also note that the terrestrial dataset derived from observations by Kleinhans (2005) has an inverted shape relative to the majority of the other relationships. Following Wilson et al. (2009, their Eq. (16.11)) we choose as the most appropriate friction factor to describe turbulent flow in outflow channels that derived from the relationship for channels with boulder-dominated beds.

\subsection{Viscous heat production}

Heat is produced by the viscous motion of the flow, which acts to balance the heat loss rate. Hulme (1982) used a formula derived from the Navier-Stokes equation for a viscous, incompressible fluid giving the viscous heat production $Q_{\mathrm{v}}$ in the fluid per unit area of the bed, and Bargery (2007) found that an extra factor including the coefficients 1 and $v$ discussed earlier increased the precision of the expression, so that,

$$
Q_{\mathrm{v}}=\bar{u} h \rho_{\mathrm{b}} g \sin S_{\mathrm{t}}(22 \mathrm{\imath}+32 v) /(33-11 \mathrm{t}-v)
$$

where $\rho_{\mathrm{b}}$ is the bulk density of a hyper-concentrated flow. $Q_{\mathrm{v}}$ is variable in the model because $h$ decreases due to the mass loss from evaporation of the water and $\bar{u}$ is also dependent on $h$. 
Dividing $Q_{v}$ by $h$, the viscous heat flux per unit fluid volume is obtained and dividing the result by the density, the heat production rate per unit mass is obtained. This is equal to $c_{\mathrm{w}} \mathrm{d} \theta_{\mathrm{w}} / \mathrm{d} t$ where $c_{\mathrm{w}}$ is the specific heat per unit volume of the fluid; hence the rate of temperature change due to the viscous heating rate is

$$
\delta \theta_{\mathrm{w}} / \delta t=Q_{\mathrm{v}} /\left(c_{\mathrm{w}} h \rho_{\mathrm{b}}\right)
$$

For an idea of the magnitude of viscous heating, consider water without a sediment load, $\rho_{\mathrm{b}}=\sim 1000 \mathrm{~kg} \mathrm{~m}^{-3}$ and $c_{\mathrm{w}}=4186 \mathrm{~J} \mathrm{~kg}^{-1} \mathrm{~K}^{-1}$; on Mars $g=\sim 3.7 \mathrm{~m} \mathrm{~s}^{-2}$, and typical water flow speeds in channels $\sim 50 \mathrm{~m}$ deep on typical slopes of $\sin S_{\mathrm{t}}=\sim 2 \times 10^{-3}$ are $\bar{u}$ $=\sim 10 \mathrm{~m} \mathrm{~s}^{-1}$ (Fig. 4 in Wilson et al. (2009)). Hence for this example, $\partial \theta_{\mathrm{w}} / \partial t=\sim 1.8 \times$ $10^{-5} \mathrm{~K} \mathrm{~s}^{-1}$ if no heat were lost from the flow. Some outflow channels on Mars are up to $1000 \mathrm{~km}$ long (e.g., Table 1). Flowing at, say, $3 \mathrm{~m} \mathrm{~s}^{-1}$ the time taken by a given batch of water to reach this distance would be $\sim 3 \times 10^{5}$ s ( 83 hours or 3.5 days). During this time the temperature rise due to viscous heat production would be $6.3 \mathrm{~K}$.

\subsection{Evaporation}

The rate of loss of water from the flow will depend on the driving mechanism of evaporation, whether by boiling or diffusion into the atmosphere. This in turn will be influenced by the water temperature and hence by the amount of latent heat removed by the evaporation process itself and by the sensible heat lost to heating up ice and silicates in cryosphere material eroded from the bed of the channel and entrained into the flow.

Previous analyses, except for some analyses of flow in valley networks, e.g., Heldmann et al. (2005), have been concerned primarily with the heat balance after a permanent ice cover has formed on a Martian flood (Wallace and Sagan, 1979; Carr, 1983), but evaporative processes must be treated also for the stage where ice has not 


\section{ACCEPTED MANUSCRIPU}

yet formed. The following analysis improves the current estimates of the time required for a flow to cool to its freezing point, and subsequently to lose its latent heat, given the initial flow thickness and water temperature. The time-scales for these processes are, in part, controlled by the heat loss rate from the surface of the flow, in turn controlled partly by the volume lost to the atmosphere through evaporation as a fraction of the total volume of water remaining in the flow.

The water evaporation is controlled by three physical regimes (Wallace and Sagan, 1979): (1) evaporation due to the difference between the atmospheric pressure and the water vapour pressure; (2) buoyant diffusion; and (3) evaporation through forced convection by the wind. These three mechanisms are now discussed in turn.

\subsubsection{Evaporation due to water vapour pressure}

Evaporation of water exposed on the surface of Mars will continue as long as the water remains warm enough for its vapour pressure to exceed the atmospheric pressure. Kennard (1938) gives a formula for calculating the mass loss rate per unit area due to the difference between the vapour pressure of water and the partial pressure of water in the atmosphere. This formula is valid if the vapour pressure of water exceeds the atmospheric pressure.

The temperature of the water, $\theta_{\mathrm{w}}$, at a particular point along the flow is a controlling factor of the vapour pressure (e.g., Clifford and Hillel, 1983; Kaye and Laby, 1995) and hence evaporative cooling. Although the empirical relationships used by various workers are similar for water temperatures $<273.15 \mathrm{~K}$, there is some discrepancy between authors for temperatures $>273.15 \mathrm{~K}$. However, this discrepancy is negligible over the pressure range experienced at the surface of Mars (Bargery, 2007; Bargery et al., 2010). One may therefore use a single equation that covers the range of $P_{\mathrm{a}}$ observed on Mars. In this study, that of Allison and Clifford (1987) is used because the expression gives a water vapour pressure curve that is similar to the 
average curve of all of the expressions compared by Bargery (2007), and it also covered well the desired range of water temperatures:

$$
\begin{aligned}
& P_{v}=133.3 \exp \left[\frac { - 5 6 3 1 . 1 2 0 6 } { \theta _ { w } } \square 1 8 . 9 5 3 0 4 \operatorname { l o g } _ { 1 0 } \theta _ { w } \left[-0.03861574 \theta_{w}\right.\right. \\
& \square 2.77494 \times 10^{-5} \theta_{w}^{2}-15.55986
\end{aligned}
$$

The vapour pressure of water at $273.15 \mathrm{~K}$ is $610.7 \mathrm{~Pa}$, which is the atmospheric pressure that occurs near the datum on the surface of Mars, leading to suggestions that the Martian atmospheric pressure may be buffered by the triple point of water (e.g., Jakosky, 1986). The melting point of water ice is very weakly dependent on the pressure applied to the ice. This dependency is important when considering, for example, the melting point of water at the top of Europa's proposed oceans, but the change in the melting point is negligible over the range of pressures that occur on the surface of Mars.

The near-surface atmospheric conditions (pressure and temperature) on Mars are highly variable, depending upon altitude, latitude, time of year, and time of day, (e.g., Hourdin et al., 1993). Therefore, although global models of pressure as a function of spatial position are available for the present epoch (e.g., Lobitz et al., 2001), they may not be applicable to earlier Amazonian times and they are more complex than required here. There remain many unknowns for past conditions at the times of outflow channel floods, not least the precise times of their occurrences. The atmospheric pressure, $P_{\mathrm{a}}$, varies depending on season and altitude. Since it is unknown at what time of year the floods occurred, no account is taken of the variation of $P_{\mathrm{a}}$ with season. As one of the aims of this work is to produce a generic model that can be applied to any Amazonian outflow channel, the atmospheric pressure $P_{\mathrm{a}}$ is assumed to 
depend only on altitude in the model, as described by, e.g., Schofield and Barnes (1997):

$$
P_{\mathrm{a}}=P_{0} \exp \left(-h_{\mathrm{ad}} / h_{\text {scale }}\right)
$$

where $P_{0}$ is the atmospheric pressure at height above datum (altitude) $h_{\mathrm{ad}}=0$, assumed to be $610 \mathrm{~Pa}$, and $h_{\text {scale }}$ is the scale height, $11 \mathrm{~km}$ on Mars. As the flow proceeds downhill, the altitude decreases as

$$
h_{\mathrm{ad}}=h_{\text {ado }}-L \tan S_{t}
$$

where $h_{\mathrm{ad} 0}$ is the altitude at the source, or proximal end of the channel, and $L$ is the horizontal distance from the source that the flow has travelled. We find that the resulting pressure increase is quite significant over the long distances travelled by the outflow channels. For example, $600 \mathrm{~km}$ downstream from its proximal end, Mangala forks into two branches. From its head region to this point, the floor of Mangala decreases in elevation from 0 to $500 \mathrm{~m}$ below the datum (Ghatan et al., 2005; Burr et al., 2009), giving an average value of $\tan S_{\mathrm{t}}=0.00083$, and a pressure difference between the source region and the mouth region of $\sim 28 \mathrm{~Pa}$. For Athabasca Valles, the elevation of the channel varies from $-2400 \mathrm{~m}$ at the source region (e.g., Burr et al., 2009) to $\sim 3 \mathrm{~km}$ below datum at the distal end in the Cerberus Plains (e.g., Plescia, 2003), a change of $\sim 600 \mathrm{~m}$ that correlates to a pressure variation of $\sim 34 \mathrm{~Pa}$. The effect of this increase of pressure is investigated and the results are discussed in section 4 . Since the water is cooling at the same time, the vapour density increases. The saturation density of the water vapour $\rho_{\mathrm{sv}}$ with a molecular mass of $M_{\mathrm{w}}$ can be calculated by rearranging the ideal gas equation: 


$$
\rho_{\mathrm{sv}}=\frac{P_{v} M_{w}}{Q \theta_{\mathrm{wv}}}
$$

where $P_{\mathrm{v}}$ is the vapour pressure of the water, $\theta_{\mathrm{wv}}$ is the temperature of the water, and $Q$ is the universal gas constant, $8.314 \mathrm{~kJ} \mathrm{kmol}^{-1} \mathrm{~K}^{-1}$. Eq. 12 can also be used to calculate the density of $\mathrm{CO}_{2}$ vapour using the appropriate molecular mass.

\subsubsection{Evaporation by buoyant diffusion}

Buoyant diffusion results from the presence of an unstable stratification of the atmosphere occurring because the saturated near-surface atmosphere is lighter than the overlying unsaturated $\mathrm{CO}_{2}$ atmosphere, since the molecular mass of water vapour, $18.02 \mathrm{~kg} / \mathrm{kmol}$, is less than that of $\mathrm{CO}_{2}, 44.01 \mathrm{~kg} / \mathrm{kmol}$ (e.g., Haberle and Jakosky, 1990).

Ingersoll (1970) defines a ratio $\Delta \rho / \rho$, where $\Delta \rho$ is the "difference between the density of the ambient gas [carbon dioxide] and that of the gas at the surface [carbon dioxide and water]", and " $\rho$ is the total density of gas [carbon dioxide and water] at the surface". An expression for $\Delta \rho / \rho$ is (Ingersoll, 1970)

$$
\Delta \rho / \rho=\frac{M_{c}-M_{w}{ }^{-} P_{v}}{M_{c} P_{a}-M_{c}-M_{w} P_{v} \sqsubset}
$$

where $M_{\mathrm{c}}$ is the molecular mass of $\mathrm{CO}_{2}$, and $M_{\mathrm{w}}$ is the molecular mass of $\mathrm{H}_{2} \mathrm{O}$. Ingersoll's equation of evaporation rate due to buoyant convection is in terms of the difference between the water vapour concentration (by mass) of the gas at the evaporating surface and that of the gas away from the surface, but is more useful when written in terms of $\rho_{\mathrm{sv}}$ (Eq. 12) and $\Delta \rho / \rho$ : 


$$
E_{\text {free }}=0.17 \rho_{\mathrm{sv}} D\left[\frac{\Delta \rho}{\rho} \frac{g}{\xi^{2}}\right]^{13}
$$

where $\xi$ is the kinematic viscosity of carbon dioxide, $\Delta \rho / \rho$ is given by equation (13), and the diffusivity coefficient of water vapour $D$ in an atmosphere of pressure $P_{a}$ and temperature $\theta_{\mathrm{a}}$, assumed to be constant equal to $210 \mathrm{~K}$, is given by

$$
D=1.654 \times 10^{-5}\left[\frac{\theta_{a}}{273.15}\right]^{32}\left[\frac{1.013 \times 10^{5}}{P_{a}}\right]
$$

Rather than using a constant value for the kinematic viscosity of the atmosphere, $\xi$, as did Wallace and Sagan (1979), here $\xi$ is calculated as the ratio of the dynamical viscosity, $\mu_{\mathrm{a}}$, to the density of the carbon dioxide atmosphere, without water, at the surface, $\rho_{\mathrm{a}}$ :

$$
\xi=\mu_{\mathrm{a}} / \rho_{\mathrm{a}}
$$

$\xi$ is therefore a dependent variable throughout a run of the model. Wallace and Sagan (1979) quote a least-square polynomial fit to the empirical data of Sutherland and Maass (1930) and Johnston and McCloskey (1940) for the dynamical viscosity of the atmosphere, $\mu_{\mathrm{a}}$. In fact, both the units and the equation itself are inaccurate as quoted by Wallace and Sagan (1979) (see Bargery, 2007). Rather, it should read, from the original references and converting to SI units:

$$
m_{a}=\llbracket 0.002162 q_{a}^{2} \square 3.771 q_{a} \square 172.01 \rrbracket / 10^{8} \mathrm{~Pa} \mathrm{~s}
$$


From Eq. (13), considering the values for the molecular mass of $\mathrm{CO}_{2}$ and $\mathrm{H}_{2} \mathrm{O}$, $\Delta \rho / \rho=13 /\left(\left(22 P_{\mathrm{a}} / P_{\mathrm{v}}\right)-13\right)$. Therefore, if $P_{\mathrm{a}} / P_{\mathrm{v}}<0.5909$ then mass loss due to free convection ceases because $\Delta \rho / \rho=0$ and both processes are dependent on $\Delta \rho / \rho$. Physically, this corresponds to the water vapour remaining near the top of the flow. This is a more realistic approach than that of previous workers.

\subsubsection{Evaporation by the wind}

Since the Martian atmosphere is continually dynamic, as evidenced by the frequent dust storms, the next physical regime to be considered is evaporation by the wind, i.e., forced convection. Wallace and Sagan (1979) concluded that, "since wind and free convection both seem to influence evaporation perceptibly, the simplest approach to include them both would be to add their effects." The mass loss rate due to evaporation by the wind (Ingersoll, 1970) is given by $E_{\text {wind }}=0.002 \rho_{\mathrm{sv}} u_{\mathrm{p}}$, where $u_{\mathrm{p}}$ is the physical wind velocity, which depends on the critical wind velocity $u_{\mathrm{c}}$ and the frictional wind velocity $u_{\mathrm{f}}$, assumed here as $0.3 \mathrm{~m} \mathrm{~s}^{-1}$, as follows. From the kinematic viscosity given by Eq. (16), the critical wind velocity may be calculated as $u_{\mathrm{c}}=2.5 \xi$ $/ z_{0}$, where $z_{0}$ is a roughness length characteristic of the surface, assumed to be $0.033 \mathrm{~m}$. If the frictional wind velocity, $u_{\mathrm{f}}$, is greater than $u_{\mathrm{c}}$ then the wind blows in a turbulent fashion, and the physical wind velocity is described by

$$
\left.\left.u_{p}=u_{f}\right\rceil \frac{1}{\kappa_{\mathrm{vk}}}\right\rceil \ln \left\lceil\frac{u_{f} \chi}{v}\right]
$$

where $\kappa_{\mathrm{vk}}$ is the Von Karman constant equal to 0.4 and $\chi$ is the height above which the atmosphere is dry. Else, the wind flows smoothly, and the physical wind velocity is described by an alternative expression: 


$$
u_{p}=u_{f}[5.5 \square]\left[\frac { 1 } { \kappa _ { \mathrm { vk } } } \left[\ln \left[\frac{u_{f} \chi}{v}\right][]\right.\right.
$$

We propose that this is an improvement over the method of Carr (1983), who assumed rough air flow and used a constant value for $u_{\mathrm{p}}$. For both smooth and rough air flow, the thickness of the laminar sub-layer of the near-surface atmosphere $d$ is given by $d=$ $30 v / u_{\mathrm{f}}($ Sverdrup, 1937).

Gaidos and Marion (2003) assume that the air passing over the surface is initially dry. The current model predicts whether the air will be dry or not, by calculating the height above the ground above which the air is dry $(\chi)$, which is a function of the width of the channel, $W$, because the water can continue to provide vapour molecules to the wind for a greater time if the wind that carries them away blows over a greater distance. The faster the wind is blowing, the fewer water vapour molecules are blown away and hence the lower $\chi$, giving the relationship $\chi=W \eta / u_{\mathrm{p}}$ (Wallace and Sagan, 1979). Although this relationship has been mentioned by previous workers, it has not been solved for $\chi$, given $W$ and $u_{\mathrm{f}}$, probably as it requires a numerical solution because there are two unknowns. In order to calculate $\chi$ for a given width of the body of water over which the wind blows, the physical velocity of the wind must be compared with the velocity of the water molecules rising buoyantly from the water surface. This diffusive process has a characteristic velocity $\eta$ of (Wallace and Sagan, 1979)

$$
\eta=\frac{1}{\left[\frac { d } { D } \square \left[\left[\frac{1}{\kappa_{\mathrm{vk}} u_{f}}\left[\ln \left[\frac{\chi+z_{0}}{d+z_{0}}\right][]\right]\right.\right.\right.}
$$


where $d$ is the thickness of the laminar sub-layer, equal to $30 \xi / u_{\mathrm{f}}$. To show how $\chi$ varies explicitly with $W$ and $u_{\mathrm{f}}$, our model solves equation (20) iteratively, using Newton's method. Ten iterations ensure that $\chi$ is determined to the same precision as $W$.

To summarize, the rate of evaporation is dependent on the vapour pressure of water, buoyantly diffusive molecules, and the wind. All these phenomena, and hence the dominant mechanism of evaporation, vary as a function of surface temperature (Bargery, 2007; Bargery et al., 2010; Fig. 3). Figure 3 shows the dependence of the mass flux of water vapour per unit area on the surface temperature for each of the three processes of evaporation. Our model is more realistic model than that of Gaidos and Marion (2003), who assume that the transfer of water vapour from the flow to the air takes place only by forced convection (i.e., the wind). At temperatures between 273.15 and $\sim 320 \mathrm{~K}$, buoyant diffusion dominates given wind speed, but evaporation due to the vapour pressure dominates at all temperatures $<\sim 320 \mathrm{~K}$ and wind speeds $>$ $0.3 \mathrm{~m} \mathrm{~s}^{-1}$, by up to $\sim 3$ orders of magnitude, near the freezing point, for reasonable wind speeds. As the frictional wind speed increases, the dominance of the wind increases over the vapour pressure effect. At temperatures $<273.15 \mathrm{~K}$, the vapour pressure effect ceases. Evaporation due to buoyant diffusion is many orders of magnitude less than evaporation due to the wind at temperatures $<273.15 \mathrm{~K}$, and does not operate above the freezing point. Evaporation due to the difference between the vapour pressure and the atmospheric pressure does not operate below the freezing point (Bargery, 2007; Bargery et al., 2010).

The water depth reduction rate while water is cooling to its freezing point is calculated by dividing the total mass loss rate per unit area, $E_{\mathrm{tot}}$, by the water density, hence

$$
\mathrm{d} h / \mathrm{d} t=E_{\mathrm{tot}} / \rho_{\mathrm{w}}
$$


where $t$ is time, and $E_{\mathrm{tot}}$ is the mass of water lost per unit surface area, given by $E_{\mathrm{tot}}=$ $E_{\text {pres }}+E_{\text {free }}+E_{\text {wind. }}$ Loss rates due to evaporation decrease with decreasing temperature because the vapour pressure also decreases with temperature.

The latent heat of evaporation $L_{\mathrm{e}}$, is weakly dependent on the temperature of the water, according to $L_{\mathrm{e}}=2.5 \times 10^{6} \mathrm{~J} \mathrm{~kg}^{-1}-2730.1 \theta_{\mathrm{w}}$, and is used to calculate the heat flux from the exposed water surface to the atmosphere. The heat flux from the surface of the water due to evaporation, $Q_{\mathrm{cw}}$ is given by the product of the mass loss rate per unit area and the latent heat of evaporation;

$$
Q_{\mathrm{cw}}=L_{\mathrm{e}} E_{\mathrm{tot}}
$$

\subsection{Mass and Heat Exchange due to Erosion of Cold Regolith}

Previous workers (Carr, 1983; Kreslavsky and Head, 2002) have modelled the conductive heat loss to the regolith, $Q_{\mathrm{cr}}$, either numerically or analytically, as a heat balance problem. However, many uncertainties arise concerning estimates of complex factors such as water turbulence and the local geothermal gradient in the regolith. There has also been a lack of consideration of the incorporation of ground ice. Flows that carve small gullies may have low erosion rates that require consideration of $Q_{\mathrm{cr}}$ explicitly but, for catastrophic floods of the scale that have eroded the outflow channels, the erosion rate is of a different order of magnitude and the heat transfer process is different.

An appropriate alternative approach is to consider that most of the heat lost by the water at the base of the flow is used to warm cold material eroded from the surface. The Martian surface most likely comprises loose rock, which is stripped away easily but varies in depth from place to place, lying over a more consolidated layer, which includes both rock and ice. The bulk of eroded material will likely be the 
underlying more competent layer consisting of both ice and rock. The heat loss from the water to this material is equal to that required to warm and melt the ice and warm the cold rock. This argument is valid as long as the erosion rate exceeds the thermal wave penetration depth into the regolith. A thermal wave penetrates to a depth of $\sim(\pi$ $\kappa t)^{1 / 2}$, where $\kappa$ is the thermal diffusivity and $t$ the time, $=1 \mathrm{~mm}$ in 1 second. Hence, if the erosion rate is on the order of at least $1 \mathrm{~mm}$ per second, then by the time the particles are entrained into the flow, they should have just warmed up at the expense of the heat contained within the water and rock already in the flow; in this way no additional heat is lost to the ground from the system.

Ice may be present in the water derived from two origins: (1) ice eroded from the regolith and (2) ice crystals that form due to freezing of the water. The second process (freezing) once the water temperature $\theta_{\mathrm{w}}$ becomes equal to $273.15 \mathrm{~K}$ is caused by further heat loss due to evaporation and heat loss due to warming of the eroded material, which only occurs if erosion occurs. Therefore, origin 2 is affected by the magnitude of origin 1.

Erosion of the surface materials results in a sediment load that includes ice, which is assumed to comprise up to $\sim 15 \%$ of the cryosphere at less than $1 \mathrm{~km}$ depth (e.g., Hanna and Phillips, 2005). If $\theta_{\mathrm{w}}>\theta_{\mathrm{f}}$ (the water freezing point), then the eroded ice is melted by the water (also, no ice crystals are formed by freezing). Any melted ice contributes to the total volume of water in the flow, and the contribution is determined by the ratio of the density of ice to the density of water. By considering the heating of the bedload rock and ice to $\theta_{\mathrm{f}}$, the heat required to melt the ice, and the subsequent heating up to temperatures above freezing where necessary, one can calculate the effect of loading the water with eroded cold rock and ice. The thermal consequences of eroding given depths of rock, $d_{\mathrm{r}}$, and ice, $d_{\mathrm{i}}$, into a flow of current total depth $h$ at $\theta_{\mathrm{w}}>\theta_{\mathrm{f}}$ may be found by the following treatment. 
The heat $Q_{\mathrm{r}}$ required to warm the eroded material from its original ground temperature to a temperature, $\theta_{\mathrm{eq}}$, at which all of the material in the flow is at thermodynamical equilibrium, may be considered as a sum of: (1) the latent heat required to melt the ice, (2) the heat required to raise the temperature of the eroded rock to the equilibrium temperature $\theta_{\mathrm{eq}}$, (3) the heat required to raise the temperature of the ice to the melting point, and (4) the heat required to raise the temperature of the melted ice (i.e., water) to $\theta_{\text {eq. }}$. All ice will melt when $\theta_{\mathrm{w}}>273.15 \mathrm{~K}$ and will contribute a depth of water $i_{\mathrm{wt}}$ to the total flow depth, calculated from the ratio of the densities of water and ice. $Q_{\mathrm{r}}$ is then given in terms of the equivalent depths of rock, water and ice, which are added to the flow due to erosion by a given amount, by

$Q_{r}=\rho_{i} d_{i} L_{f}+\rho_{i} d_{i} c_{i} \sqsubset \theta_{f}-\theta_{c} \sqsubset+\rho_{r} c_{r} d_{r} \sqsubset \theta_{\mathrm{eq}} \hat{-} \theta_{c} \sqsubset+\rho_{w} i_{\mathrm{wt}} c_{w} \sqsubset \theta_{w}-\theta_{f} \sqsubset$

where $\theta_{\mathrm{f}}$ is the freezing point temperature of water, $\theta_{\mathrm{w}}$ is the temperature of the water before incorporating bedload, $\theta_{\mathrm{c}}$ is the surface temperature of the cryosphere, $L_{\mathrm{f}}$ is the latent heat of fusion of ice, $334.9 \mathrm{~kJ} \mathrm{~kg}^{-1}, c_{\mathrm{w}}, c_{\mathrm{r}}, c_{\mathrm{i}}$ are specific heats and $\rho_{\mathrm{w}}, \rho_{\mathrm{r}}, \rho_{\mathrm{i}}$ are densities, of water, rock and ice, respectively. $c_{\mathrm{i}}$ depends on the temperature of the ice, whereby $c_{\mathrm{i}}=7.037 \theta_{\mathrm{c}}+185 \mathrm{~J} \mathrm{~kg}^{-1} \mathrm{~K}^{-1}$, but since $\theta_{\mathrm{c}}$ is assumed to be constant equal to $210 \mathrm{~K}, c_{\mathrm{i}}$ is also constant at $1663 \mathrm{~J} \mathrm{~kg}^{-1} \mathrm{~K}^{-1} . c_{\mathrm{r}}$ is also assumed constant at $800 \mathrm{~J} \mathrm{~kg}^{-1} \mathrm{~K}^{-}$ ${ }^{1}, \rho_{\mathrm{r}}=2700 \mathrm{~kg} \mathrm{~m}^{-3}$ and $\rho_{\mathrm{i}}=914 \mathrm{~kg} \mathrm{~m}^{-3}$. The model therefore neglects the small effect of eroding into a temperature profile, because the geothermal gradient is not precisely known. $Q_{r}$ is taken from the heat currently contained in the flow, which consists of an absolute equivalent depth of water, $d_{\mathrm{w}}$, and an absolute depth of rock $R_{\mathrm{d}}$ (zero at time zero, and distinguished as the current rock depth rather than the rock depth eroded in the current time increment), at $\theta_{\mathrm{w}}>273.15 \mathrm{~K}$, before the water has begun to freeze (at these temperatures, $h=d_{\mathrm{w}}+R_{\mathrm{d}}$ ). As erosion continues, the heat lost by these depths of water and rock in cooling to $\theta_{\text {eq }}$ are $\left[\rho_{\mathrm{w}} d_{\mathrm{w}} c_{\mathrm{w}}\left(\theta_{\mathrm{w}}-\theta_{\mathrm{eq}}\right)\right]$ and $\left[\rho_{\mathrm{r}} R_{\mathrm{d}} c_{\mathrm{r}}\left(\theta_{\mathrm{w}}-\right.\right.$ 
$\left.\left.\theta_{\mathrm{eq}}\right)\right]$ respectively (note that the rock and water already in the flow are at the same temperature). Equating the sum of these heat losses to $Q_{\mathrm{r}}$, then

$$
\begin{aligned}
& \rho_{w} d_{w} c_{w} \theta_{w}-\theta_{\mathrm{eq}} \sqsubset+\rho_{r} c_{r} R_{d} \square \theta_{w}-\theta_{\mathrm{eq}} \equiv \\
& \rho_{i} d_{i} L_{f}+\rho_{i} d_{i} c_{i} \theta_{f}-\theta_{c} \sqsubset+\rho_{r} c_{r} d_{r} \theta_{\mathrm{eq}}-\theta_{c} \sqsubset+\rho_{w} i_{w t} c_{w} \theta_{w}-\theta_{f} \sqsubset
\end{aligned}
$$

With algebraic manipulation, equation (24) can be written in terms of the change in temperature of the water, $\Delta \theta_{\mathrm{w}}\left(=\theta_{\mathrm{w}}-\theta_{\mathrm{eq}}\right)$, due to entrainment of given depths of cold rock and ice:

$$
\begin{aligned}
& \Delta \theta_{\mathrm{w}}=\rho_{\mathrm{i}} d_{\mathrm{i}} L_{\mathrm{f}}+\rho_{\mathrm{i}} d_{\mathrm{i}} c_{\mathrm{i}}\left(\theta_{\mathrm{f}}-\theta_{\mathrm{c}}\right)+\rho_{\mathrm{r}} \mathrm{c}_{\mathrm{r}} \mathrm{d}_{\mathrm{r}}\left(\theta_{\mathrm{w}}-\theta_{\mathrm{c}}\right)+\rho_{\mathrm{w}} \mathrm{i}_{\mathrm{wt}} \mathrm{c}_{\mathrm{w}}\left(\theta_{\mathrm{w}}-\theta_{\mathrm{f}}\right) /\left(\rho_{\mathrm{w}} \mathrm{d}_{\mathrm{w}} \mathrm{c}_{\mathrm{w}}+\rho_{\mathrm{r}}\right. \\
& \left.\mathrm{c}_{\mathrm{r}} \mathrm{d}_{\mathrm{r}}+\rho_{\mathrm{w}} \mathrm{i}_{\mathrm{wt}} \mathrm{c}_{\mathrm{w}}+\mathrm{R}_{\mathrm{d}} \rho_{\mathrm{r}} \mathrm{c}_{\mathrm{r}}\right)
\end{aligned}
$$

Eq. (25) is valid for $\theta_{\mathrm{w}}>\theta_{\mathrm{f}}$. As $\theta_{\mathrm{w}}$ decreases with time, and approaches the freezing point of water, the temperature change due to erosion of bedload decreases. All the ice is assumed to melt and the rock is assumed to warm to the equilibrium temperature within the time increment of the model (10 seconds). The rate of temperature change due to erosion is dependent on the rate of erosion, discussed in Section 3.1. The total absolute depth $d_{\mathrm{b}}$ of material eroded from the base over a given time increment $\Delta t$ is

$$
d_{\mathrm{b}}=e \Delta t
$$

where $e$ is the erosion rate. When $\theta_{\mathrm{w}}>\theta_{\mathrm{f}}$, then in each time increment, the eroded material added to the system cools the flow by an amount given by Eq. (25).

3.7. Mass and Heat Exchange due to Evaporation and Flow 
While the temperature of the flow is above the freezing point, the actual rate of temperature change of the water is a function of the heat balance between heat loss due to evaporation, viscous heat production, and heat loss by warming eroded sediment. From the combined cooling and heating rates, the time required to cool the flood to the freezing point is calculated in the model. Since the flow is well mixed by turbulence, the whole body is at the same bulk temperature and will cool to the freezing point at the same time. For laminar flow, this would not be the case, and a different model would have to be used. The net rate of cooling of the water in the turbulent case is given by

$$
\mathrm{d} \theta_{\mathrm{w}} / \mathrm{d} t=\left(Q_{\mathrm{cw}}+Q_{\mathrm{r}}-Q_{\mathrm{v}}\right) /\left(c_{\mathrm{w}} h \rho_{\mathrm{w}}\right)
$$

where $c_{\mathrm{w}}$ is the specific heat capacity of water.

\subsection{Freezing of the water}

At the freezing point, the water will lose its latent heat of fusion as ice crystals form. Both water and ice temperatures are buffered at the triple point since the ice crystals are in thermodynamic equilibrium with the water. The flow will continue to travel while ice crystals are forming. For water temperatures $\theta_{\mathrm{f}}$, ice eroded from the substrate does not melt, and the temperature of the water does not decrease until all the latent heat has been lost; any eroded ice present at $273.15 \mathrm{~K}$ will be in thermodynamic equilibrium with the water. There is no addition to the depth of water in the flow from melting of eroded ice. However, since cold material continues to be eroded after the temperature of the water has decreased to $273.15 \mathrm{~K}$, this material will still be warmed to $\theta_{\mathrm{f}}$ (as $\theta_{\mathrm{f}}>\theta_{\mathrm{c}}$ ). This removes heat from the water, causing further ice crystal formation. The rate of formation of ice crystals due to this heat loss from the water can be calculated by consideration of the latent heat of freezing. The depth 
fraction $\varsigma$ of ice produced from this heat loss, written in terms of absolute depths of rock, water, and ice as before, is

$$
V=\frac{q_{f}-q_{c-\cdots} d_{i}+d_{r-}\left[q \rho _ { i } c _ { i } \square \left[1-q\left[\rho_{r} c_{r}\right]\right.\right.}{d_{w} \rho_{w} L_{f}}
$$

where $q$ is the depth fraction of the cryosphere that is ice, assumed to be 0.15 (Clifford, 1993; Hanna and Phillips, 2005). The increase in ice fraction is at the expense of the fraction of water, but ice is less dense than water so the decrease in water fraction is slightly less than the increase in ice fraction.

\subsection{Yield strength and viscosity of flow}

Even if erosion ceases, the liquid water in the flow will continue to freeze whatever the flow regime because of latent heat loss through evaporation at the flow surface. Any ice present in the flow will be buoyant due to its lower density compared with water. As long as the flow is well stirred and an ice raft does not form, the water temperature will remain buffered at the freezing point. As ice crystals are formed in such a flow, the turbulent velocity will initially exceed the buoyant vertical velocity of the ice crystals, so that the crystals will be entrained within the flow and will not immediately segregate to the top of the flow to form incipient ice rafts.

With entrainment of sediment and ice and/or formation of ice crystals by freezing, the solid content increases, the bulk viscosity increases and the fluid becomes non-Newtonian. Generally, non-Newtonian suspensions exhibit a finite yield strength, $\sigma_{y}$, that needs to be overcome for flow to take place; as $\sigma_{y}$ increases, the tendency for the flow to be turbulent decreases. A number of rheometrical studies of clay-water mixtures have been made (e.g., Gay et al., 1969; Coussot and Piau, 1994; Coussot, 1995) but these are essentially for moderate solid volume fractions $(<0.1)$ or 
at high shear rates $\left(>10 \mathrm{~s}^{-1}\right)$. Several relationships between greater solid fractions and yield strength for a range of flow conditions have been proposed from empirical data and theoretical treatments. Some workers (Julien, 1995) provide approximate relationships to find the yield strength of an aqueous mixture with a total solids volume fraction $\varphi>0.05$. The corresponding dynamic viscosity of the flow $\mu$ is also given by some workers. Gay et al. (1969) propose that, at low strain rates, the flow viscosity depends on the flow capacity $\varphi_{\max }$. Bargery (2007) compared the viscosity increase factor of several workers, which is the ratio of the viscosity of the flow to the viscosity of the water, $\mu_{0}$, without any solids, at the triple point temperature. In our model, we use the expression of Julien (1995) derived from empirical relationships where the grain size of the sediment load is mainly between silts and clays,

$$
m=m_{0}[1 \square[2.5 \mathrm{j}[\square \exp \llbracket 23[j-0.05 \llbracket]
$$

The relationship given by Menand and Phillips (2007) yields the same viscosity increase factor as that of Gay et al. (1969), if a flow capacity of 1.0 solids fraction is used in the latter's equation. This implies that Menand and Phillips (2007) do not account for flow capacity, and in most other studies this is the case, because previous work has tended to study solid volume fractions $<0.4$. The kinematic viscosity of the flow, $\xi_{\mathrm{f}}$, is derived from the dynamic viscosity, $\mu$, by $\xi_{\mathrm{f}}=\mu / \rho_{\mathrm{b}}$.

The yield strength and the viscosity of a fluid always increase rapidly as the solids fraction increases beyond $\sim 0.3$ and reach extremely large values when $\varphi$ approaches a critical value (taken to be equal to the flow capacity) found to be $\varphi_{\max } \sim$ 0.6 (Abrahams et al., 2001). As the results show, in our model solutions $\varphi$ never exceeds 0.68 while the flow is turbulent so that this is not a significant issue. An expression for the yield strength, $\sigma_{\mathrm{y}}$, for turbulent flow, even up to very high solid fractions, can be derived from a curve fitted to the empirical data of Huang and Garcia 
(1998), Parsons et al. (2001) and Bowles et al. (2003) for fine-grained sediments (Fig.

3); we find:

$$
\sigma_{y}=0.1341 \exp [10.14 \phi
$$

3.10. Bingham model for turbulent flow

In most models of turbulent, sediment-loaded water flows with yield strength, the simplest form of non-Newtonian fluid, a Bingham fluid, has been used to describe simple shear behaviour. Bingham models provide a reasonable compromise between accuracy and simplicity, and they have been frequently used to describe the rheology of hyper-concentrated flows, mudflows, and debris flows (Pastor et al., 2004). The Bingham plastic is characterised by two dimensionless numbers, the Reynolds number $R e$ defined by (e.g., Knudsen and Katz, 1954)

$$
\operatorname{Re}=\left(4 \bar{u} h \rho_{\mathrm{b}}\right) / \mu
$$

and the Hedström number He (e.g., Skelland, 1967), a measure of the ratio of the fluid's yield strength to the shear stress applied to the flow

$$
H e=\left(16 h^{2} \sigma_{\mathrm{y}} \rho_{\mathrm{b}}\right) / \mu^{2}
$$

where $h$ is the flow depth, $\bar{u}$ is the mean flow speed, $\rho_{\mathrm{b}}$ is the bulk density of the flow, and $\mu$ is the flow viscosity. These parameters control the laminar-turbulent transition, as described in the next section. Equations (31) and (32) are valid if the mean channel width, $W>h$, which is the case for the outflow channels. The bulk density of the flow is given by: 
At water temperatures close to the triple point the viscosity of water $\mu_{0}$ is $\sim 1.5 \times 10^{-3}$

Pa s and the density $\rho_{\mathrm{w}}$ is close to $1000 \mathrm{~kg} \mathrm{~m}^{-3}$ so the Reynolds number of a flow of water without sediment is approximately $8 \times 10^{8}$, implying extreme turbulence. This situation is modified by the erosion of sediment and ice, and by the formation of ice crystals due to freezing of the water. Our model tracks the changes in the Reynolds number and Hedström number, and finds when the motion becomes laminar.

A Bingham fluid thermally convects spontaneously only when the Reynolds number exceeds a certain critical threshold, $R e_{\text {crit. }}$ If thermal convection occurs in a Bingham fluid, it operates in cells (Gershuni and Zhukhovitskii, 1973) sheared at their boundaries, the sizes of the cells being determined by the smallest physical length scale, in this case the depth of the flow.

\subsection{Turbulent to laminar transition}

A requirement for the flow to remain turbulent is that $R e$ must remain greater than a critical value $R e_{\text {crit }}$ that is itself an increasing function of $H e$. Transition from turbulent to laminar flow in Bingham fluids therefore occurs at substantially higher $R e$ values than for Newtonian fluids. We fit a function to the experimental data quoted by Skelland (1967):

$$
R e_{\text {crit }}=10^{(3.3737014-(0.1286522 * \log (\mathrm{He}))}+\left(0.0462269(\log (\mathrm{He}))^{2}\right)
$$

If $R e$ decreases to a value close to $R e_{\text {crit, }}$, turbulence will begin to be damped out (Skelland, 1967). As the volume fraction of ice in the flow increases, as discussed earlier, both $R e$ and $R e_{\text {crit }}$ decrease. However, $R e$ decreases at a faster rate than $R e_{\text {crit }}$ and eventually the turbulent to laminar transition is reached. In practice we track both 
$R e$ and $R e_{\text {crit }}$ and force the turbulent-to-laminar transition as soon as the two become equal. Thereafter the motion remains laminar until topography or complete freezing stop the motion. In laminar flow the friction factor is inversely proportional to the Reynolds number, and so when laminar motion is established the friction factor is found by taking the friction factor for turbulent flow at the critical Reynolds number and multiplying it by the ratio of $R e_{\text {crit }}$ to $R e$.

\section{Application, Results and Interpretation}

As described earlier, group (c) parameters were varied to find the conditions under which a flow can travel a distance equal to the observed channel length for each of the two well-documented Amazonian outflow channels, Mangala and Athabasca Valles. The corresponding best-fit values of $h_{0} l a$, and the implied time to erode the observed length, was found for each channel. Maximum outflow distance, $X_{\max }$, while the flow is erosive, is plotted in Fig. 4 as a function of $h_{0} / a$ for a flow in Mangala Valles, to illustrate the way in which the model results are affected by variation in the initial water depth. We use as a mean channel depth $60 \mathrm{~m}$ for Mangala, and find that the best-fit value of $h_{0} / a$ is $5 / 6$, hence $h_{0}=50 \mathrm{~m}$. The model was run with a range of initial water depths for each channel, from bank-full (100\% of the observed channel depth), and at $10 \%$ decrements down to $10 \%$ of the observed mean channel depth, in order to test how sensitive the model results are to initial water depths. The graphical results presented in Figs. 5 to 14 are obtained from application of the model to both Mangala Valles (part (a) of each figure) and Athabasca Valles (part (b) of each figure) with best-fit values of $h_{0} / a$. The results are non-unique solutions, and are only one set of results that are consistent with the observations. Other, similar combinations of factors such as $D_{50}$ (the bed clast size such that $50 \%$ of clasts are smaller than this size), initial water temperature, and initial water depth could yield the same results. The results are summarised in Table 1. 
As hypothesised in section 2, four flow stages can be identified from the results for Athabasca Valles, as outlined in sections 4.1 to 4.4. However, for Mangala Valles, stage 2 is not present, because $D_{\max }$ is always less than $D_{50}$, meaning that most of the sediment is transported as bedload, which is perhaps counter-intuitive because of the fine grain size (sand) best-fit for the mean particle size. The flow in Athabasca transitions from stage 1 to stage 2 after $15 \mathrm{~km}$, to stage 3 after $93 \mathrm{~km}$, and to stage 4 at $355 \mathrm{~km}$ from the source, only $5 \mathrm{~km}$ greater than the observed erosion length of Athabasca. For Mangala, the flow transitions from stage 1 to stage 3 after $23 \mathrm{~km}$, and to stage 4 after $855 \mathrm{~km}$, again the observed erosion length of the channel to the required precision.

\subsection{Flow stage 1}

At the very proximal end of the channels, no erosion occurs when the flow velocity is $<3 \mathrm{~m} / \mathrm{s}$. However, this limit is soon exceeded and flow thickness (Fig. 8) increases in stage 1 because, although water is being lost through vigorous boiling and evaporation, both rock and ice are being eroded by the flow and the equivalent 'depths' of both of these contribute to the total flow thickness. Stage 1 could be split into two sub-stages, where in stage 1a cooling is dominated by the stronger influence of boiling and where in Stage $1 \mathrm{~b}$ cooling is controlled more by the increasing effect of heat transfer from the water to melt eroded ice. The rock contributes directly - the depth of rock eroded equals the depth of rock in the flow, and the ice contributes indirectly, because the ice transported by the flow during stage 1 is melted, thereby adding to the depth of water in the flow. Water depth therefore also increases during stage 1. Evaporation due to the difference between the atmospheric pressure and the vapour pressure of water is the dominant evaporative process at the proximal end, where $\theta_{\mathrm{w}}>273.15 \mathrm{~K}$, and the altitude of the outflow channels was sufficiently high for the atmospheric pressure to be less than the vapour pressure, so that this process 
could occur (Fig. 5). The flow cools initially very rapidly to the freezing point due to evaporation and forced convection through boiling at the surface (Fig. 6); this has a dominant effect over that of ice melting on the mass balance of liquid water, hence the water depth decreases initially. Soon, however, the ice melting dominates over the boiling, so that the addition of liquid water is greater than the removal by boiling. The results show that the time required for a turbulent flood with a release temperature of $313 \mathrm{~K}$ to begin to freeze, which is the point that defines the end of stage 1 (Fig. 6), depends on the initial flow depth. Ice crystals do not form by freezing of the water until the temperature decreases to $273.15 \mathrm{~K}$.

\subsection{Flow stage 2}

The flow transitions to stage 2 when the heat loss rate from the flow surface decreases as the vapour pressure curve responds to the freezing of the water. The water depth begins to decrease after the water has cooled to the freezing point because (a) of dominant importance, there is no longer any addition to the water depth from melted, eroded ice, (b) evaporation causes water mass loss, and (c) evaporative heat loss continues to cause freezing and further loss of liquid mass. While it is true that freezing of water to ice causes a volume increase, and hence an increase in flow depth, there is a loss of liquid mass, which causes a contemporaneous decrease in water depth. We account for the volume increase due to freezing, while studying the transfer of mass from liquid to solid states. Once $\theta_{\mathrm{w}}=\theta_{\mathrm{f}}$, the evaporation due to the vapour pressure becomes zero (Fig. 5). The net mass loss rate decreases to a constant value that depends on the wind speed when the flow decreases to the freezing point of water. Once the atmospheric pressure becomes greater than the vapour pressure, the only evaporative agent operating is evaporation by the wind, but the effects of the wind are only noticeable near to the source, and become negligible once the surface temperature of the flow is at the freezing point. In conclusion, evaporation is only a 
significant factor in the proximal parts (stage 1) of the outflow channels. Thereafter, in stages 2 and 3, the flow cools primarily due to stripping sediment from the bed, which becomes the dominant cooling process as the bulk temperature of the flow remains at a value close to the freezing point. There is a change in gradient of the graphs of both viscosity and density, caused by initiation of the formation of ice crystals within the flow once the water begins to freeze. After the water begins to freeze, the total volume fraction of ice in the flow is a sum of the eroded ice that does not melt and the ice formed by freezing.

\subsection{Flow stage 3}

All of the thermodynamical processes such as evaporation and cooling of the flow, and sedimentological processes such as erosion and transportation, which occur in stage 2, also occur in stage 3 . The only major difference between stages 2 and 3 is the mode of transportation of sediment, where in stage 2 , more than $50 \%$ of sediment is transported as washload, and in stage 3, the dominant mode is bedload. Hence, flow in Mangala Valles experiences similar processes to flow in Athabasca, but does not strictly go through stage 2, but rather skips to stage 3 . The flow in Mangala Valles increases from a thickness of $\sim 50 \mathrm{~m}$ at the source of the flood, to $\sim 115 \mathrm{~m}$ by the end of stage 3. These large flow thicknesses can be explained by the fact that the channels have such great lengths that the flow entrains so much material that, although the water depth declines, the flow thickness increases. Flow velocity (Fig. 7) ranges from $\sim 5$ for Athabasca to $\sim 12 \mathrm{~m} / \mathrm{s}$ for Mangala. In all the channels, the flow accelerates towards the distal end of the channel, while still in the turbulent regime. Both viscosity and density of the flow increase with time as the solid fraction increases. Fig. 9 shows the way in which the viscosity of the flow evolves through time as the solids volume fraction (Fig. 10) changes. The viscosity increases because of continued ice crystal formation, and the bulk density decreases, partly through freezing of water to 
ice. The values for $D_{50}$ and $D_{84}$ for Athabasca Valles were those assumed by Kleinhans (2005), who corrected the grain size distribution inferred by Wilson et al. (2004) from early Mars surface lander data. With these values we were able to model a flow that covered the observable eroded distance. However, when these values were tested for flow in Mangala Valles, the maximum outflow distance for initially bankfull flow was $482 \mathrm{~km}$, well short of the observed $850 \mathrm{~km}$ length of the channel. Hence other combinations of values for $D_{50}$ and $D_{84}$ were tested, and we found that one proposed by Herkenhoff et al. (2004) for a sand-dominated sediment particle size distribution based on higher-resolution Mars lander data yielded a flow that could travel $850 \mathrm{~km}$ with an initial water depth of $50 \mathrm{~m}$ (Table 1).

\subsection{Flow stage 4}

For both of the channels, the flow transitions to laminar (Fig. 11) when $R e$ decreases to less than $R e_{\text {crit }}$ due to the incorporation of rock and ice during stages 1-3. Once the flow becomes laminar, the flow velocity decreases rapidly, and once the flow speed is less than $2 \mathrm{~m} / \mathrm{s}$, deposition can occur. Hence deposition probably occurred in the distal end of each channel as a result of the insufficient energy of the flow for transportation.

\section{Discussion}

The transit times of the floods are listed in Table 1. These are the times taken for the flood to cover the observed length of each outflow channel before the flow regime transitions to laminar (Fig. 11), which is a requirement if the outflow channels were carved by a single flood containing liquid water, assuming that the floods were fully erosive while turbulent but erosion was negligible when the flow was laminar. This assumption is supported by the apparent absence of depositional fans at the distal ends of the eroded channels, though it is possible that later lava deposits may have 


\section{ACCEPTED MANUSCRIPT}

buried such fans at Athabasca (Kesthelyi et al., 2000). The transit times are greater than the period of 6.7 hours calculated by the baseline model of Andrews-Hanna and Phillips (2007) for the time that had elapsed when peak discharge, on the order of $10^{6}$ to $10^{7} \mathrm{~m}^{3} \mathrm{~s}^{-1}$, occurred in Ares Vallis. If their model is applicable to all of the Amazonian outflow channels and similar results are obtained, this would suggest that flow conditions would change after the discharge declined. The minimum discharge in Ares Vallis is reached after 23 days (Andrews-Hanna and Phillips, 2007). The transit times in Table 1 are all less than this period. However, the transit times indicate how long it would take for a parcel of water in a flow to travel the distance of a channel, and not the total time for all of the water to discharge from the source aquifer and flow to the distal end of the channel. For an order-of-magnitude comparison, we note that for a parcel of water to travel $1000 \mathrm{~km}$ at $10 \mathrm{~m} / \mathrm{s}$ requires $10^{5} \mathrm{~s}$, which are typical values (Table 1), and also that to erode a $100 \mathrm{~m}$ layer of bed at $1 \mathrm{~mm} / \mathrm{s}$ (a typical value of mean erosion rate, Table 1) needs the same time, $10^{5} \mathrm{~s}$. For specific estimates of the flood durations for each of the two channels, we divide the mean depth by the erosion rate in each case. We obtain (from Table 1) $60 \mathrm{~m} / 0.69 \mathrm{~mm} / \mathrm{s}=86956 \mathrm{~s}=\sim 24$ hours for Mangala and $100 \mathrm{~m} / 0.76 \mathrm{~mm} / \mathrm{s}=131578 \mathrm{~s}=37$ hours for Athabasca. Therefore, the floods could have eroded, and established the lengths of, the observed channels during what amounts to a single $\sim 30$ hour "pulse" of water, not a protracted flood lasting a few days (Baker and Milton, 1974; Carr, 1979) to 1-3 months (Ghatan et al., 2005). Leask et al. (2007) estimated the flood duration in Mangala Valles to be $\sim 17$ days if the sediment carrying capacity of the water had been $40 \%$ by volume, or $\sim 46$ days if the sediment load had been $20 \%$ by volume. We note that in a real channel, as discharge declines, erosion will continue longer in the proximal parts than the distal parts, which could cause significant differences in incision depth. It is evident from Table 1 that, for both channels, the flow transit times are a few hours less than the estimated flood durations. The model results therefore show that the first parcel of a 


\section{ACCEPTED MANUSCRIPT}

flow will reach the distal end of a channel before the whole channel depth has been eroded.

The mean erosion rates from Table 1 are several times greater than those estimated by previous workers (e.g. Komar, 1979; Coleman and Dinwiddie, 2005) from estimates of flood durations, and the erosion rates at the proximal ends of the channels are as great as $\sim 20 \mathrm{~mm} \mathrm{~s}^{-1}$, due to the effect of thermal erosion. However, the erosion rate decreases rapidly with time and distance from the source (Fig. 14). The mean erosion rates are only one order of magnitude more than those commonly observed in channel flows on Earth. Such rapid erosion as given by the model results at the proximal ends of the channels is usually achieved by the removal of large grain sizes of material from the channel; the Bonneville flood, for instance, achieved erosion rates on the order of $0.1 \mathrm{~mm} / \mathrm{s}$ by eroding $10 \mathrm{ft}$ boulders. However, the model results show that the best-fit grain size is sand for both channels; hence our assumption of thermal equilibrium is valid, along with our discussion of rheological changes. If, however, much of the bed load is made up of anything larger than sand, then our assumption of near-instantaneous thermal equilibration between the eroded material and the water would be invalid. Gravel and boulders incorporated into the flow are unlikely to warm up much during a flood lasting a few hours. Less heating of large boulders in a given period would mean less cooling of the material currently in the flow which in turn would imply more capacity of the flow to melt ice downstream. The implications of such a modification are complex and would require further modelling of such a scenario. However, assuming thermal equilibrium is attained rapidly, then the model results show that it is therefore possible that the outflow channels were eroded by single flooding events; hence it is not possible to reject our original hypothesis. However, this is not to exclude the possibility of multiple floods.

The thalweg of Mangala Valles (Fig. 15) has a range of elevation from $+500 \mathrm{~m}$ to $-300 \mathrm{~m}$, i.e., of $800 \mathrm{~m}$. The channel depth has decreased by $90 \%$ (to $-220 \mathrm{~m}$ ) after 
a distance of $\sim 60 \mathrm{~km}$. The model predicts that the erosion rate, and therefore the eroded depth per time increment (Fig. 14) will have decreased by $91 \%$ after $60 \mathrm{~km}$, showing an excellent agreement between data and model. Some workers (e.g., Golombek et al., 1999) have suggested very high erosion rates for the outflow channels. In this case, the flow would become laminar rapidly due to the increase in effective viscosity from entrained sediment and decrease in turbulence because ice crystal segregation might not be able to counteract the decreasing $R e$. The flow would stop eroding its base after distances much shorter than the observed channel lengths due to the rheological and thermodynamic effects of eroding and transporting cold material. Such high erosion rates may occur at the proximal ends of channels, but sustained high erosion rates for the entire flow are incompatible with the model results.

Following the conceptual model presented earlier (Fig. 1), and the results obtained from the computer model, it is now possible to give estimates of the durations of each of the stages in the conceptual model. Stage 1 is likely to last no longer than a maximum of 1 hour, stage 2 , if present, is likely to last on the order of 4 hours, and stage 3 will be the longest in duration, lasting up to $\sim 19$ hours. It is not yet possible to estimate the duration of stage 4 , since the formation of an ice raft has not been modelled fully, although during this time the flow would freeze fully, possibly forming moraine-like deposits such as those described by Chapman et al. (2007). Subsequent sublimation of an ice layer several tens of metres thick could take years, and the time-scale of sublimation could be extended by the likely presence of rock and sediment layers within the ice layers; however, a complete discussion of this awaits further work. We stress here that the above durations apply only to an individual parcel of water, as it progresses along a channel, not to the durations of different parts of an entire flood event (any particular stage will continue to occur somewhere within the channel for most of the duration of a flood event), and that they would be 
correspondingly greater for larger outflow channels. More than one flow stage will be occurring within the flood as a whole at any given time after the first parcel of water (the head of the flood) has reached the distal end of a channel. These values are estimates based on the flow conditions in our model, as applied to the two Amazonian examples of outflow channels. These combinations of flow conditions are non-unique solutions for the travel time of a flow to erode the channels; hence this is a first-order estimate that nevertheless supports the hypothesis for high discharge, short-duration, single floods having eroded the channels.

The model stages are compared with the bed-forms found in Athabasca Valles at various distances from the source of the flood-water, Cerberus Fossae, in Fig. 16. The pristine topography (Fig. 16a) and morphology of the Athabasca Valles has provided some indication of the flood-water flow characteristics. A set of transverse linear forms in the channel (Fig. 16b), corresponding with model stage 2, were analysed and shown to have dune morphology (Burr et al., 2004). Inferred to be floodformed dunes, they indicate that the flood-water flow was sub-critical, but turbulent, at the location and time of their formation (Burr et al., 2004). The model results (Figure 11b) for $F r$ and $R e$ during stage 2 in Athabasca Valles are consistent with these observations (Fig. 16c), showing that $R e>R e_{\text {crit }}$ and $F r<1$, which are standard tests for dunes to form in fluvial settings (e.g., Huggett, 2003). Unfortunately there is a sparsity of analysis of bedforms along the entire lengths of the outflow channels, so that we are only able to state where bedforms such as dunes have been recorded. If there is anywhere dunes do not occur "upstream" of the transition between stages 3 and 4 in the model, there would then be a discrepancy between model and observation. Fig. 11 shows that ripples may form in both channels during stage 4, when $F r<<1$ and the flow is laminar.

Fig. 16d shows an example of deposits at a distance from the source corresponding to model stage 3 , towards the second half of this stage. The origin of 
these deposits, possibly volcanic (Keszthelyi et al., 2000, 2004), or possibly involving ice in some form (Burr et al., 2005; Murray et al., 2005), is controversial (see Page and Murray, 2006 for a discussion). If these deposits are ice-dominated, then this may imply that ice raft formation occurs earlier than we have supposed, in the latter part of stage 3 rather than in stage 4 , when turbulence is being damped out, but before $R e$ reaches $R e_{\text {crit }}$ In reality, we envisage that there will be a continual feedback system, where, in the first instance, $R e$ decreases sufficiently for the buoyant rise velocity of the ice crystals to exceed the turbulent velocity and ice crystals begin to rise to the surface of the flow. The water beneath the forming ice raft will now contain fewer solid particles and hence the flow turbulence will increase. Further erosion and freezing will result in a further decrease in turbulence, but then ice will again rise to the surface. This cycle will continue until stage 4 is reached, whilst the ice raft will thicken continuously due to addition of ice to its base. Once stage 4 is finally reached and the entire flow becomes laminar, this cycle will cease. According to our model, erosion will also practically cease, so that the flow will continue to cool through heat loss by conduction through the ice raft and into the underlying ground.

Kleinhans (2005) suggested that very large velocities $\left(\sim 150 \mathrm{~m} / \mathrm{s}\right.$ for $D_{50}$, even up to $>250 \mathrm{~m} / \mathrm{s}$ for larger median grain sizes) are required to form hyperconcentrations of gravel by entrainment from the bed. Fig. 12 shows that if the median grain size is $0.1 \mathrm{~m}$ (gravel, as used by Kleinhans), then lower flow velocities than suggested previously are capable of entraining gravel. The required flow velocity for Mangala is $\sim 80 \mathrm{~m} / \mathrm{s}$. However, these velocities are still an order of magnitude greater than the respective velocities that actually occurred in the channel flows (Fig. 7). Fig. 13 presents the variation of the maximum diameter of the suspended sediment, $D_{\max }$, with time. During stages 1 and 2 in Athabasca Valles, $D_{\max }>D_{50}$, implying that the flow conditions in this channel are such that it is possible for at least $50 \%$ of the sediment to be transported as suspended load, even with a large $(0.1 \mathrm{~m})$ median grain 
diameter, as suspected for the channel flows. This is due in part to the settling velocities being correspondingly low, whereby the transportation of large volume fractions in a hyper-concentrated flow inherently inhibits the settling of large boulders and transports them in washload. This is not the case for Mangala Valles, for which the flow does not have the transport capability to carry the majority of its sediment as washload, but rather the dominant transport mode is bedload. This difference may be explained by the fact that flow speed is greater in Mangala because of the greater slope, and this in turn increases the erosion rate. Increased erosion leads to greater yield strength of the flow and hence damping of turbulence, which leads to a dominant sediment transport mode by bed-load. Again, this shows the power of the continualfeedback within the model. Eventually for Athabasca, and very early for Mangala (while the flow is still in stage 1 ), $D_{\max }$ decreases to such an extent that $D_{50} \geq D_{\max }$, from which point most of the sediment is transported as bedload; this is taken to signify a new stage, 3 . During the whole of stages 3 and $4, D_{50} \geq D_{\max }$. Unfortunately, there is little knowledge to constrain the particle size distribution in each flow, which could be compared with Fig. 13 to show the proportion of sediment transported as washload, as a function of time for each channel flow. It is not therefore possible to find the precise value of $\varphi_{\mathrm{w}}$. So, it is not yet possible to reject the hypothesis that at least $50 \%$ of the sediments could have been transported as washload (Komar, 1980), and it remains unknown whether up to $60-70 \%$ weight of the sediment transported by the outflow channel flows was transported as wash load.

Our model assumes continuity of discharge within a flow of water, so that the cross-section of water examined by the model is followed by more water at the same discharge rate. The whole length of the flow follows behind the head of the flow, so that when a flow becomes laminar at the distal end of a channel and begins to deposit sediment and an ice raft begins to form, the ice and sediment within the following water can pile up against the frontal, preceding parts of the flow, as well as behind 
obstructions. This action may continue until the flow discharge decreases. The fact that continuity in a single flood event must be violated at the distal end when the fluid stops moving means that there will be episodic distal depositional events even if there is only one release event. However, a higher-discharge subsequent event may travel further than an earlier event and erode some of its distal deposits.

\section{Conclusions}

A model of channelized water flow under the current Martian atmospheric and climatic conditions has been presented, with particular emphasis on the outflow channels, to test the hypothesis that they each formed as a consequence of the action of a single flood of water. The model has been applied to two Amazonian-age channels, the Mangala and Athabasca Valles, and the results show that it is not possible to reject this hypothesis. The model results imply that:

(1) Outflow channel water flows were in all cases fully turbulent when first released.

(2) Both heat loss from the upper flow surface by evaporation and forced atmospheric convection and heat transfer to cold ice and rock eroded from the cryosphere at the flow base were critically important in determining the subsequent flow development, the balance shifting from the former to the latter with increasing distance from source.

(3) The bed erosion rate decreased greatly when laminar flow was achieved and a balance evolved between erosion of ice and fine silicates from the bed and deposition of coarse silicates from the flow. Flow velocity also decreased sharply at the turbulent to laminar transition.

(4) The bed erosion rates found for both Mangala and Athabasca Valles are similar (Table 1), approximately $0.7 \mathrm{~mm} \mathrm{~s}^{-1}$, which is greater by up to a factor of $\sim 3$ 
than those estimated by Leask et al. (2006b) based on estimates of both flood duration and water volume required to erode a volume of rock from Ravi Vallis.

(5) The dominant sediment transport mode changes from washload to bedload during flow in outflow channels, before the flow regime transitions to laminar.

(6) According to the model results, catastrophic outbursts in the Amazonian had short water transit times down the resulting channels, but discharges from the sources probably continued for a longer period than the transit time of an individual water parcel down the channel.

(7) Both Mangala and Athabasca Valles could have been eroded by a waterbased flood under current environmental surface conditions of low pressure and low temperature, without the need for a warmer climate.

(8) Multiple flooding may well have occurred in both Mangala and Athabasca Valles, as suggested by other authors, but we have demonstrated that single floods could have eroded these channels.

A range of possible further applications is envisaged for this model: (1) to study water flowing on the surfaces of other solar system bodies; (2) to study flowing water released from any melting ice layer (e.g., an ice cap or an ice sheet); (3) to study sub-glacial flow and subsequent release of water during sub-glacial eruptions forming jökulhlaups; (4) to investigate possible mechanisms of rapid flooding of the northern lowlands of Mars (Baker, 1982; Wilson and Head, 2003); and (5) to investigate the flow properties and conditions of other outflow channel floods on Mars. 


\section{Acknowledgements}

The authors are much obliged to Devon Burr and Keith Harrison for their thorough, helpful, and informative reviews of this manuscript. ASB would also like to thank Sanjeev Gupta and Harry Pinkerton for reviewing his thesis, part of which formed the basis for this paper. 


\section{References}

Abrahams, A. D., Li, G., Krishnan, C., Atkinson, J. F. 2001. A sediment transport equation for interrill overland flow on rough surfaces. Earth Surface Processes and Landforms 26, 1443-1459.

Allison, M. L., Clifford, S. M. 1987. Ice-covered water volcanism on Ganymede. J. Geophys. Res. 92, 7865-7876.

Andrews-Hanna, J. C., Phillips, R. J. 2007. Hydrological modeling of outflow channels and chaos regions on Mars. J. Geophys. Res. 112 (E8), E08001.

Baker, V. R., 1979. Erosional processes in channelized water flows on Mars. J. Geophys. Res. 84, $7985-7993$.

Baker, V. R., 1982. The Channels of Mars. University of Texas, Austin, USA.

Baker, V. R., Kochel, R. C. 1979. Martian Channel Morphology: Maja and Kasei Valles. J. Geophys. Res. 84 (B14), 7961-7983.

Baker, V. R., Milton, D. J. 1974. Erosion by catastrophic floods on Mars and Earth. Icarus 33, 27-41.

Bargery, A. S. 2007. Aqueous eruption and channel flow on Mars during the Amazonian Epoch. Ph.D. Thesis, Lancaster University, Lancaster, UK, 499 pp.

Bargery, A. S., Lane, S. J., Barrett, A., Wilson, L., Gilbert, J.S. 2010. The initial responses of hot liquid water released under low atmospheric pressures: Experimental insights. Icarus 210, 1, 488506, doi:10.1016/j.icarus.2010.06.019.

Bargery, A. S., Wilson, L. 2010. Dynamics of the ascent and eruption of water containing dissolved $\mathrm{CO}_{2}$ on Mars. J. Geophys. Res. 115, E05008, doi:10.1029/2009JE003403.

Bathurst, J. C. 1993. Flow Resistance Through the Channel Network. Channel Network Hydrology. Wiley, Chichester, 1993, pp. 69-98.

Bowles, F. A., Fass, A. W., Vogt, P. R., Sawyer, W. B., Stephens, K. 2003. Sediment properties, flow characteristics, and depositional environment of submarine mudflows, Bear Island Fan. Marine Geology 197, 63 - 74.

Burr, D. M. 2005. Clustered streamlined forms in Athabasca Valles, Mars: evidence for sediment deposition during floodwater ponding. Geomorphology 69, 242-252.

Burr, D. M., Carling, P. A., Beyer, R. A., Lancaster, N. 2004. Flood-formed dunes in Athabasca Valles, Mars: morphology, modeling, and implications. Icarus 171, 68-83.

Burr, D. M., Grier, J. A., McEwan, A. S., Keszthelyi, L. P. 2002. Repeated aqueous flooding from the Cerberus Fossae: evidence for very recently extant, deep groundwater on Mars. Icarus 155, 5373. 
Burr, D.M., Soare, R.J., Wan Bun Tseung, J.-M. Emery, J.P. 2005. Young (late Amazonian), nearsurface, ground ice features near the equator, Athabasca Valles, Mars, Icarus 178, 56-73.

Burr, D. M., Wilson, L., Bargery, A. S. 2009. Floods from Fossae: a review of Amazonian-aged extensional tectonic megaflood channels on Mars. In: Burr, D. M., Carling, P. A., Baker, V. R.. (Eds.), Megaflooding on Earth and Mars: Morphology, Modelling, and Water Release Mechanisms. Cambridge University Press, Cambridge, pp. 194-208.

Carling, P. A., Herget, J., Lanz, J. K., Richardson, K., Pacifici, A., 2009. Channel-scale erosional bedforms in bedrock and in loose granular material: character, processes and implications. In: Burr, D. M., Carling, P. A., Baker, V. R.. (Eds.), Megaflooding on Earth and Mars: Morphology, Modelling, and Water Release Mechanisms. Cambridge University Press, Cambridge, pp. 13-32.

Carr, M. H., 1974. The role of lava erosion in the formation of lunar rilles and Martian channels. Icarus 22, 1, 1-23, doi: 10.1016/0019-1035(74)90162-6.

Carr, M. H., 1979. Formation of Martian Flood Features by Release of Water from Confined Aquifers. J. Geophys. Res. 84, 2995-3007.

Carr, M. H., 1983. Stability of Streams and Lakes on Mars. Icarus 56, 476-495.

Chapman, M. G., Dumke, A., Michaels, G., Neukum, G. 2007. Possible Glacial Erosion of Interior Layered Deposit Mounds in Central Candor Chasma. AGU Fall Meeting. American Geophysical Union, Abstract \#P31C-0547.

Chapman, M. G., Gudmundsson, M. T., Russell, A. J., Hare, T. M. 2003. Possible Juventae Chasma subice volcanic eruptions and Maja Valles ice outburst floods on Mars: Implications of Mars Global Surveyor crater densities, geomorphology, and topography. J. Geophys. Res. 108 (E10), 5113, doi:10.1029/2002JE002009.

Chapman, M. G., Tanaka, K. L. 2002. Related Magma-Ice Interactions: Possible Origins of Chasmata, Chaos, and Surface Materials in Xanthe, Margaritifer, and Meridiani Terrae, Mars. Icarus 155, 324-339.

Clifford, S. M. 1993. A model for the hydrologic and climatic behavior of water on Mars. J. Geophys. Res. 98 (E6), 10973-11016.

Clifford, S. M., Hillel, D. 1983. The stability of ground ice in the equatorial regions of Mars. J. Geophys. Res. 88, 2456-2474. 
Coleman, N. M., Dinwiddie, C. L. 2005. Groundwater Depth, Cryosphere Thickness, and Crustal Heat Flux in the Epoch of Ravi Vallis, Mars. Lunar and Planetary Science Conference XXXVI, Lunar and Planetary Institute, Houston, Texas, USA, Abstract \# 2163.

Costard, F., Dupeyrat, L., Gautier, E., Carry-Gailhardis, E. 2003. Fluvial thermal erosion investigation along a rapid eroding river bank;application to the Lena river (central Siberia). Earth Surface Processes and Landforms 29, 1349-1359.

Coussot, P. 1995. Structural similarity and transition from Newtonian to non-Newtonian behaviour for clay-water suspensions. Physical Review Letters 74, 3971-3974.

Coussot, P., Piau, J. M. 1994. On the behaviour of fine mud suspensions. Rheologica Acta Rheol Acta $33,175-184$.

Gaidos, E. J., Marion, G. 2003. Geological and geochemical legacy of a cold early Mars. J. Geophys. Res. 108 (E6), 5055, doi:10.1029/2002JE002000.

Gay, E. C., Nelson, P. A., Armstrong, W. P. 1969. Flow properties of suspensions with high solids concentrations. AIChE J. 15, 815-822.

Gershuni, G. Z., Zhukhovitskii, E. M. 1973. Convective stability of a Bingham liquid. Soviet Physics Doklady Fluid Mechanics 18, 36-37.

Ghatan, G. J., Head, J. W., Wilson, L. 2005. Mangala Valles, Mars: assessment of early stages of flooding and downstream flood evolution. Earth Moon Planets 96, 1-57, doi:10.1007/s11038005-9009-y.

Golombek, M., and 54 others (1999). Overview of the Mars Pathfinder Mission: Launch through landing, surface operations, data sets, and science results. J. Geophys. Res. 104 (E4), 85238553

Gupta, S., Collier, J. S., Palmer-Felgate, A., Potter, G. 2007. Catastrophic flooding origin of shelf valley systems in the English Channel. Nature 448, 342-345.

Haberle, R. M., Jakosky, B. M. 1990. Sublimation and transport of water from the north residual polar cap on Mars. J. Geophys. Res. 95, 1423-1437.

Hanna, J. C., Phillips, R. J. 2005. Hydrological modeling of the Martian crust with application to the pressurization of aquifers. J. Geophys. Res. 110, E01004, doi:10.1029/2004JE002330.

Hanna, J. C., Phillips, R. J. 2006. Tectonic pressurization of aquifers in the formation of Mangala and Athabasca Valles, Mars. J. Geophys. Res. 111, E03003, doi:10.1029/2005JE002546. 
Head, J. W., Wilson, L. 2002. Mars: a review and synthesis of general environments and geological settings of magma-H2O interactions. In: Smellie, J. L., Chapman, M. G. (Eds.), Volcano-Ice interaction on Earth and Mars. Geological Society, London, pp. 27-58.

Head, J. W., Wilson, L., Mitchell, K. L. 2003. Generation of recent massive water floods at Cerberus Fossae, Mars by dike emplacement, cryospheric cracking, and confined aquifer groundwater release. Geophysical Research Letters 30, 1577, doi: 10.1029/2003GL017135.

Herkenhoff, K., Squyres, S. W., Arvidson, R., Bass, D. S., Bell, J. F., Bertelsen, P., Cabrol, N. A., Gaddis, L., Hayes, A. G., Hviid, S. F., Johnson, J. R., Kinch, K. M,, Madsen, M. B., Maki, J. N., McLennan, S. M., McSween, H. Y., Rice, J. W., Sims, M., Smith, P. H., Soderblom, L. A., Spanovich, N., Sullivan, R., Wang, A. 2004. Textures of the soils and rocks at Gusev Crater from Spirit’s Microscopic Imager. Science 305, 824 - 826, doi:10.1126/science.1100015.

Heldmann, J. L., Toon, O. B., Pollard, W. H., Mellon, M. T., Pitlick, J., McKay, C. P., Andersen, D. T. 2005. Formation of Martian gullies by the action of liquid water flowing under current Martian environmental conditions. J. Geophys. Res. 110, E05004, doi:10.1029/2004JE002261.

Hourdin, F., Le Van, P., Forget, F., Talagrand, O. 1993. Meteorological variability and the annual surface pressure cycle on Mars. American Meteorological Society 50, 3625-3640.

Huang, X., Garcia, M. H. 1998. A Herschel-Bulkley model for mud flow down a slope. J. Fluid Mech. $374,305-333$.

Huggett, R. J. 2003. Fundamentals of Geomorphology, Routledge Fundamentals of Physical Geography, Routledge, London, ISBN 0-415-24146-4, pp 196.

Hulme, G. 1982. A review of lava flow processes related to the formation of lunar sinuous rilles. Surveys in Geophysics 5, 245-279.

Ingersoll, A. P. 1970. Mars: Occurrence of Liquid Water. Science 168, 972-973.

Jakosky, B. M. 1986. The seasonal cycle of water on Mars. Space science reviews 41.

Johnston, H. L., McCloskey, K. E. 1940. Viscosities of several common gases between $90 \mathrm{~K}$ and room temperature. J. Phys. Chem. 44, 1038-1058.

Julien, P. Y. 1995. Erosion and sedimentation. Cambridge University Press, Cambridge, UK.

Kaye, G. W. C., Laby, T. H. 1995. Tables of Physical and Chemical Constants. Longman, London, UK.

Kennard, E. H. 1938. Kinetic theory of gases. McGraw-Hill, New York, USA.

Keszthelyi, L.P., McEwen, A.S., Thordarson, Th. 2000. Terrestrial analogs and thermal models for martian flood lavas. J. Geophys. Res. 105, 15027-15049. 
Keszthelyi, L., Thordarson, T., McEwen, A.S., Haack, H., Guilbard, M.-N., Self, S., Rossi, M.J. 2004. Icelandic analogs to martian flood lavas, Geochem. Geophys. Geosyst. 5, doi:10.1029/2004GC000758.

Kleinhans, M. G. 2005. Flow discharge and sediment transport models for estimating a minimum timescale of hydrological activity and channel and delta formation on Mars. J. Geophys. Res. 110, E12003, doi:10.1029/2005JE002521.

Knudsen, J. G., Katz, D. L. 1954. Fluid Dynamics and Heat Transfer. McGraw-Hill, New York, USA.

Komar, P. D. 1979. Comparisons of the Hydraulics of Water Flows in Martian Outflow Channels with Flows of Similar Scale on Earth. Icarus 37, 156-181.

Komar, P. D. 1980. Modes of Sediment Transport in Channelized Water Flows with Ramifications to the Erosion of the Martian Outflow Channels. Icarus 42, 317-329.

Kreslavsky, M. A., Head, J. W. 2002. Fate of outflow channel effluents in the northern lowlands of Mars: The Vastitas Borealis Formation as a sublimation residue from frozen ponded bodies of water. J. Geophys. Res. 107 (E12), 5121, doi:10.1029/2001JE001831.

Leask, H. J., Wilson, L., Mitchell, K. L. 2006a. Formation of Aromatum Chaos, Mars: Morphological development as a result of volcano-ice interactions. J. Geophys. Res. 111, E08071, doi:10.1029/2005JE002549.

Leask, H. J., Wilson, L., Mitchell, K. L. 2006b. Formation of Ravi Vallis outflow channel, Mars: Morphological development, water discharge, and duration estimates. J. Geophys. Res. 111 (E8), E08070, doi:10.1029/2005JE002550.

Leask, H. J., Wilson, L., Mitchell, K. L. 2007. Formation of Mangala Valles outflow channel, Mars: Morphological development and water discharge and duration estimates. J. Geophys. Res. 112, E08003, doi:10.1029/2006JE002851.

Lobitz, B., Wood, B. L., Averner, M. M., McKay, C. P. 2001. Special Feature: Use of spacecraft data to derive regions on Mars where liquid water would be stable. PNAS 98, 2132-2137, doi: 10.1073/pnas.031581098.

Manga, M. 2004. Martian floods at Cerberus Fossae can be produced by groundwater discharge. Geophysical Research Letters 31, L02702, doi:10.1029/2003GL018958.

Max, M. D., Clifford, S. M. 2001. Initiation of Martian Outflow Channels: Related to the Dissociation of Gas Hydrate? Geophysical Research Letters 28, 1787-1790. 
McEwen, A. S., Preblich, B. S., Turtle, E. P. 2005. The rayed crater Zunil and interpretations of small impact craters on Mars. Icarus 176, 351-381.

Menand, T., Phillips, J. C. 2007. Gas segregation in dykes and sills. Journal of Volcanology and Geothermal Research 159, 393-408.

Morgan, R. P. C., Quinton, J. N/, Smith, R. E., Govers, G., Poesen, J. W. A., Auerswald, K., Chisci, G., Torri, D., Styczen, M. E. 1998. The European Soil Erosion Model (EUROSEM): A Dynamic Approach for Predicting Sediment Transport from Fields and Small Catchments. Earth Surf. Process. Landforms 23, 527-544, doi: 10.1002/(SICI)1096-9837(199806)23:6.

Murray, J.B., Muller, J.-P., Neukum, G., Werner, S.C., van Gasselt, S., Hauber, E., Markiewicz, W.J., Head, J.W., Foing, B.H., Page, D., Mitchell, K.L., Portyankina, G. and the HRSC CoI team 2005. Evidence from the Mars Express High Resolution Stereo Camera for a frozen sea close to Mars' equator. Nature 434, 352-355.

Pacifici, A., Komatsu, G., Pondrelli, M. 2009. Geological evolution of Ares Vallis on Mars: Formation by multiple events of catastrophic flooding, glacial and periglacial processes. Icarus 202, 6077, doi:10.1016/j.icarus.2009.02.029.

Page, D. P., Murray, J. B. 2006. Stratigraphical and morphological evidence for pingo genesis in the Cerberus plains. Icarus 183, 46-54, doi:10.1016/j.icarus.2006.01.017.

Parsons, J. D., Whipple, K. X., Simoni, A. 2001. Experimental study of the grainflow, fluid-mud transition in debris flows. Journal of Geology 109, 427-447.

Pastor, M., Quecedo, M., Gonzalez, E., Herreros, M. I., Merodo, J. A. F., Mira, P. 2004. Simple approximation to bottom friction for Bingham fluid depth integrated models. Journal of Hydraulic Engineering-ASCE 130, 149-155.

Randriamazaoro, R., Dupeyrat, L., Costard, F., Gailhardis, E. 2007. Fluvial thermal erosion: heat balance integral method. Earth Surface Processes and Landforms 32, 1828-1840, doi:10.1002/esp.1489.

Rice, J. W., Parker, T. J., Russel, A. J., Knudson, O. 2002. Morphology of fresh outflow channel deposits on Mars. Lunar and Planetary Science Conference XXXIII, Lunar and Planetary Institute, Houston, Texas, USA, Abstract \#2026.

Rodriguez, J. A. P., Sasaki, S., Kuzmin, R. O., Dohm, J. M., Tanaka, K. L., Miyamoto, H., Kurita, K., Komatsu, G., Fairen, A. G., Ferris, J. C. 2005. Outflow channel sources, reactivation, and chaos formation, Xanthe Terra, Mars. Icarus 175, 36-57. 
Rodriguez, J. A. P., Sasaki, S., Miyamoto, H. 2003. Nature and hydrological relevance of the Shalbatana complex underground cavernous system. Geophysical Research Letters 30 (6), 1304, doi:10.1029/2002GL016547.

Schofield, J. T., Barnes, J. R. 1997. The Mars Pathfinder Atmospheric Structure Investigation/Meteorology (ASI/MET) experiment. Science 278, 5344, doi:10.1126/science.278.5344.1752.

Skelland, A. H. P. 1967. Non-newtonian flow and heat transfer. John Wiley and Sons, New York, USA.

Sklar, L., Dietrich, W. E., 1998. River longitudinal profiles and bedrock incision models : Stream power and the influence of sediment supply. Geophysical Monograph 107, 207-260.

Smith, L.C., Alsdorf, D.E., Magilligan, F.J., Gomez, B. Mertes, L.A.K., Smith, N.D. and Garvin, J.B. 2000. Estimation of erosion, deposition, and net volumetric change caused by the 1996 Skeidarársandur jökulhlaup, Iceland, from synthetic aperture radar interferometry. Water Resources Research 36(6), 1583-1594.

Sutherland, B. P., Maass, O. 1930. Measurements of the viscosity of gases over a larger temperature range. Canad. J. Res. 428-443.

Sverdrup, H. U. 1937. On the evaporation from the oceans. J. Marine Res. 1, 3-14.

Van Rijn, L. C. 1984. Sediment transport part II: suspended load transport. Journal of Hydraulic Engineering 110, 1613-.

Wallace, D., Sagan, C. 1979. Evaporation of ice in planetary atmospheres - Ice-covered rivers on Mars. Icaurs $39,385-400$.

Warner, N., Gupta, S., Muller, J. -P., Kim, J. -R., Lin, S. -Y. 2009. A refined chronology of catastrophic outflow events in Ares Vallis, Mars. Earth and Planetary Science Letters 288, 58-69, 10.1016/j.eps1.2009.09.008.

Whipple, K. X., Hancock, G. S., Anderson, R. S. 2000. River incision into bedrock: Mechanics and relative efficacy of plucking, abrasion, and cavitation. Geol. Soc. Am. Bull. 112, 3, 490-503, doi:10.1130/0016-7606(2000)112.

Wilson, L., Bargery, A. S., Burr, D. M. 2009. Dynamics of fluid flow in Martian channels. In: Burr, D. M., Carling, P. A., Baker, V. R. (Eds.), Megaflooding on Earth and Mars: Morphology, Modelling, and Water Release Mechanisms. Cambridge University Press, Cambridge, UK, pp. 290-311. 
Wilson, L., Ghatan, G. J., Head, J. W., Mitchell, K. L. 2004. Mars outflow channels: A reappraisal of the estimation of water flow velocities from water depths, regional slopes, and channel floor properties. J. Geophys. Res. 109, E09003, doi:10.1029/2004JE002281.

Wilson, L., Head, J. W. 2003. Oceans in the Northern Lowlands of Mars? Assessment of Dike Emplacement as a Mechanism for Rapid Release of a Confined Subcryosphere Aquifer. Lunar and Planetary Science Conference XXXIV, Lunar and Planetary Institute, Houston, Texas, USA, Abstract \#1186. 


\section{ACCEPTED MANUSCRIPT}

Figure 1. Schematic of conceptual model stages, labelled 1 to 4 , of large-scale channel flow on Mars over time (flow depth changes are not included for simplicity see text). In stage (1), the turbulent water cools to freezing temperatures due to the dominant heat loss mechanism of boiling, while eroding large boulders of ice, which is melted, and rock that take time to be broken up. In stage (2), ice accumulates within the fully-turbulent flow due to the latent heat removal by the dominant heat loss mechanism of warming the cold eroded rock and ice, while the average grain size of transported material decreases. In stage (3), less than $50 \%$ of the silicate solids fraction is transported as washload and transportation is mainly by bedload, as the viscosity and density of the hyper-concentrated flow increase until the flow transitions to laminar at the end of this stage. In stage (4), the flow is laminar and an ice raft forms on the surface of the flow, while deposition occurs. This work discusses the processes involved in the water flow in stages 1 to 3, whilst Carr (1983) deals with the ice processes involved in stage 4 (his stage 3 ).

Figure 2. Bed friction factor, $f_{\mathrm{c}}$, as a function of water depth, $d_{\mathrm{w}}$, for channel beds dominated by various grain sizes on Mars, and a terrestrial data set for comparison. Also included are data for channels with fall and pool structures and for those with a fixed bed roughness (see Wilson et al., 2009). This figure was produced using a slope of 0.005 . When the bed roughness is dominated by boulders, the friction factor is independent of bed slope.

Figure 3. Yield strength as a function of solids volume fraction using data from Bowles et al. (2003), Huang and Garcia (1998) and Parsons et al. (2001), for fine grained sediments. An exponential function has been fitted to the empirical data, giving an equation of $\sigma_{\mathrm{y}}=0.1341 \exp (10.14 \varphi)$, where $\varphi$ is the solids volume fraction, which we use in our model. 
Figure 4. Maximum run-out distance while the flow is turbulent, $X_{\max }$, as a function of $\left(h_{0} / a\right)$, for Mangala Valles, where $h_{0} / a=1$ corresponds to initially bank-full flow.

Figure 5. Mass loss rate per unit area from the surface of the flow as a function of time, (a) for a flow in Mangala Valles, (b) for a flow in Athabasca Valles. Dashed lines represent evaporation due to the pressure difference between $P_{\mathrm{v}}$ and $P_{\mathrm{a}}$; dotted lines represent evaporation by the wind with a physical velocity of $0.03 \mathrm{~m} \mathrm{~s}^{-1}$.

Figure 6. Bulk water temperature (top) and corresponding heat flux (bottom) from the surface of a flow in (a) Mangala Valles, and (b) Athabasca Valles, as functions of time.

Figure 7. Flow velocity (top) and distance the flow has travelled (bottom) as functions of time, for a flow in (a) Mangala Valles, and (b) Athabasca Valles. The distance over which a given batch of water has been travelling is derived from the time and the changing flow speed.

Figure 8. Thickness of the flow (top), and the depth of the water in the flow (bottom), as functions of time, for a flow in (a) Mangala Valles, and (b) Athabasca Valles.

Figure 9. Bulk viscosity (solid lines) and bulk density (dotted lines) of a flow as a function of time, for (a) Mangala Valles, and (b) Athabasca Valles.

Figure 10. Volume fractions of the flow that are water (dashed lines), rock (dotdashed lines) and ice (dotted lines), against time, for a flow in (a) Mangala Valles, and 


\section{ACCEPTED MANUSCRIPT}

(b) Athabasca Valles. Also shown is the total solids volume fraction (solid lines) of each flow.

Figure 11. Reynolds (solid lines), Hedström (dashed lines), Critical Reynolds (dotted lines), and Froude (dot-dashed lines) numbers against time, for a flow in (a) Mangala Valles, and (b) Athabasca Valles.

Figure 12. Washload concentration as a function of velocity, for a flow in (a) Mangala Valles, and (b) Athabasca Valles, both showing the velocity at sub-saturation (at the peak velocity), using Eq. (53) in Kleinhans (2005) and a median grain size of $0.1 \mathrm{~m}$.

Figure 13. Maximum particle diameter of sediment (solid lines) that can be transported as washload (i.e., in suspension), and settling velocity (dotted lines), as functions of time, for a flow in (a) Mangala Valles, and (b) Athabasca Valles.

Figure 14. Erosion rate (solid lines) and dynamic shear stress (dotted lines) as functions of time for a flow in (a) Mangala Valles, and (b) Athabasca Valles.

Figure 15. Mangala Valles thalweg as a function of distance, $X$, from the source, Mangala Fossae. Data read from topographic cross-sections at various points along the channel from Ghatan et al. (2005).

Figure 16. (a) MOLA shaded relief overlain with MOLA colour-coded topography showing the discernibly-eroded length of Athabasca Valles, annotated with model distances (dashed lines) from the source, Cerberus Fossae (labeled CF), where the model flow transitions between each stage of the flow, as defined in the text. The 


\section{ACCEPTED MANUSCRIPT}

black arrows donate the direction of paleoflow towards the western Cerberus Plains, and the grey arrows depict where distributary channels have formed by breaching of the wrinkle ridge bordering the southern edge of the channel; (b) MOC2-862a: cPROTO image R12-03203, illustrating an example of bedforms in Athabasca Vallis: flood megaripples, formed during stage 2 of a flood. North to top, illumination is from bottom left, 2 m/pixel. Image Credit: NASA/JPL/Malin Space Science Systems. (c) Another example of bedforms formed during flow stage 2: a mosaic of MOC narrowangle images showing a cluster of streamlined forms in Athabasca Valles, inferred by previous workers (see text) to have been formed by hydraulic damming/ponding, surrounded by longitudinal lineations. Scattered small impact craters with bright ejecta are secondaries from Zunil Meteorite (McEwen et al., 2005). North is up, illumination is from the left. Image credit: Malin Space Science Systems; (d) Southern part of Mars Orbiter Camera image E10-00998, illustrating an example of deposits formed during flow stage 3, interpreted as channelised platy deposits by Page and Murray (2006). North to left, illumination from bottom left, $6.15 \mathrm{~m} /$ pixel. Image Credit: NASA/JPL/Malin Space Science Systems. 


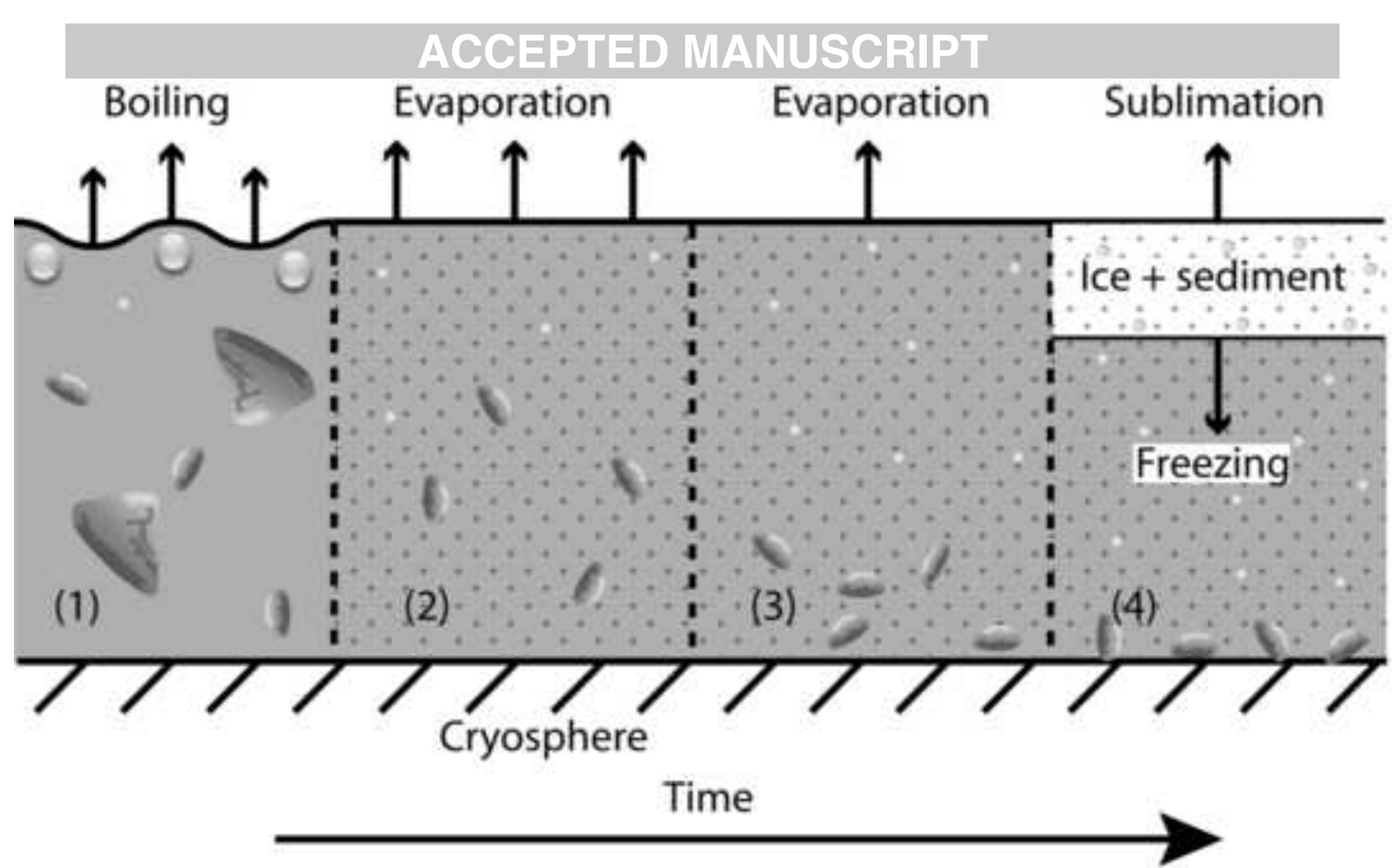

Liquid water

Solid ice

Ice crystals in water

Eroded rock and ice of various grain sizes

Gas bubbles 


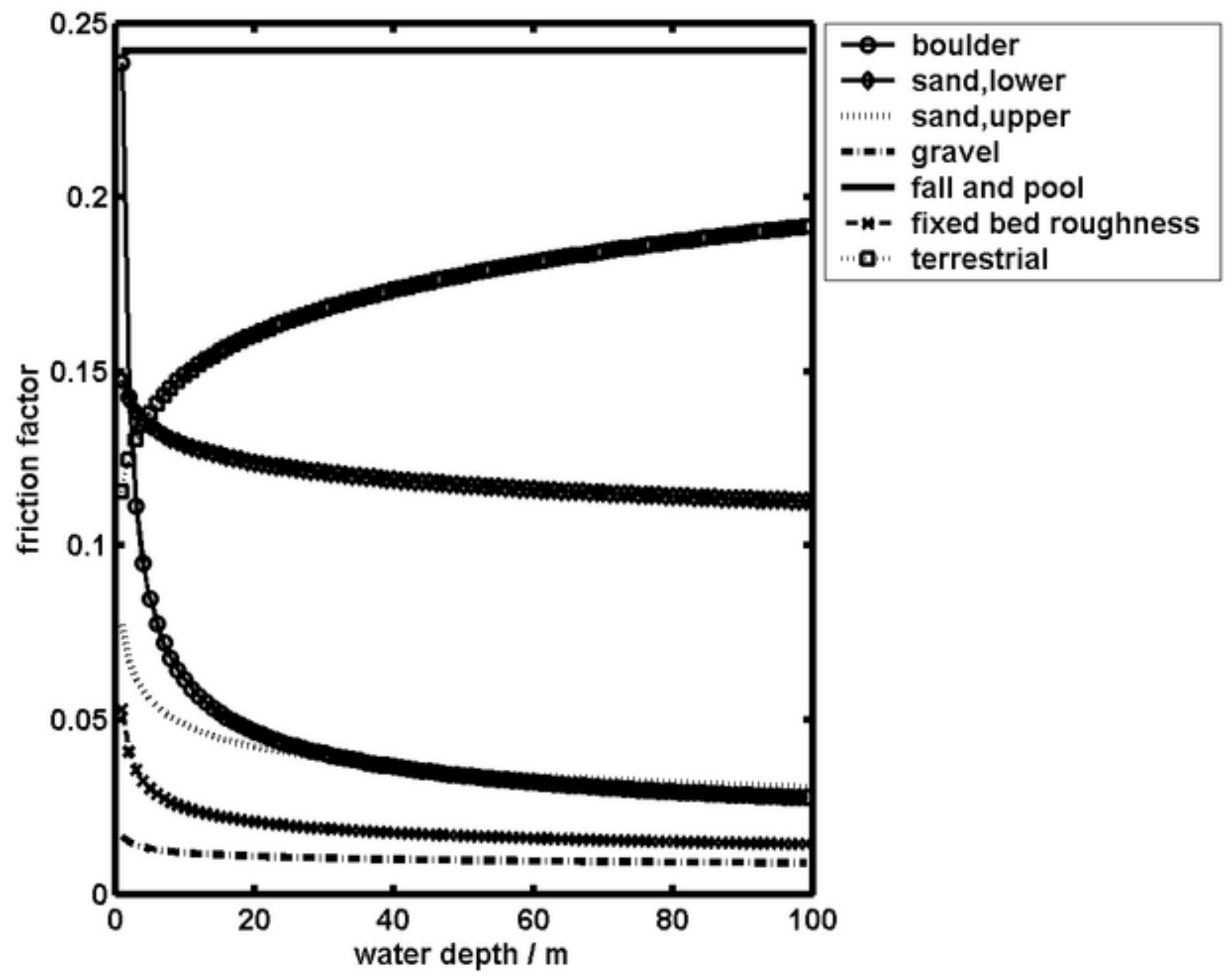




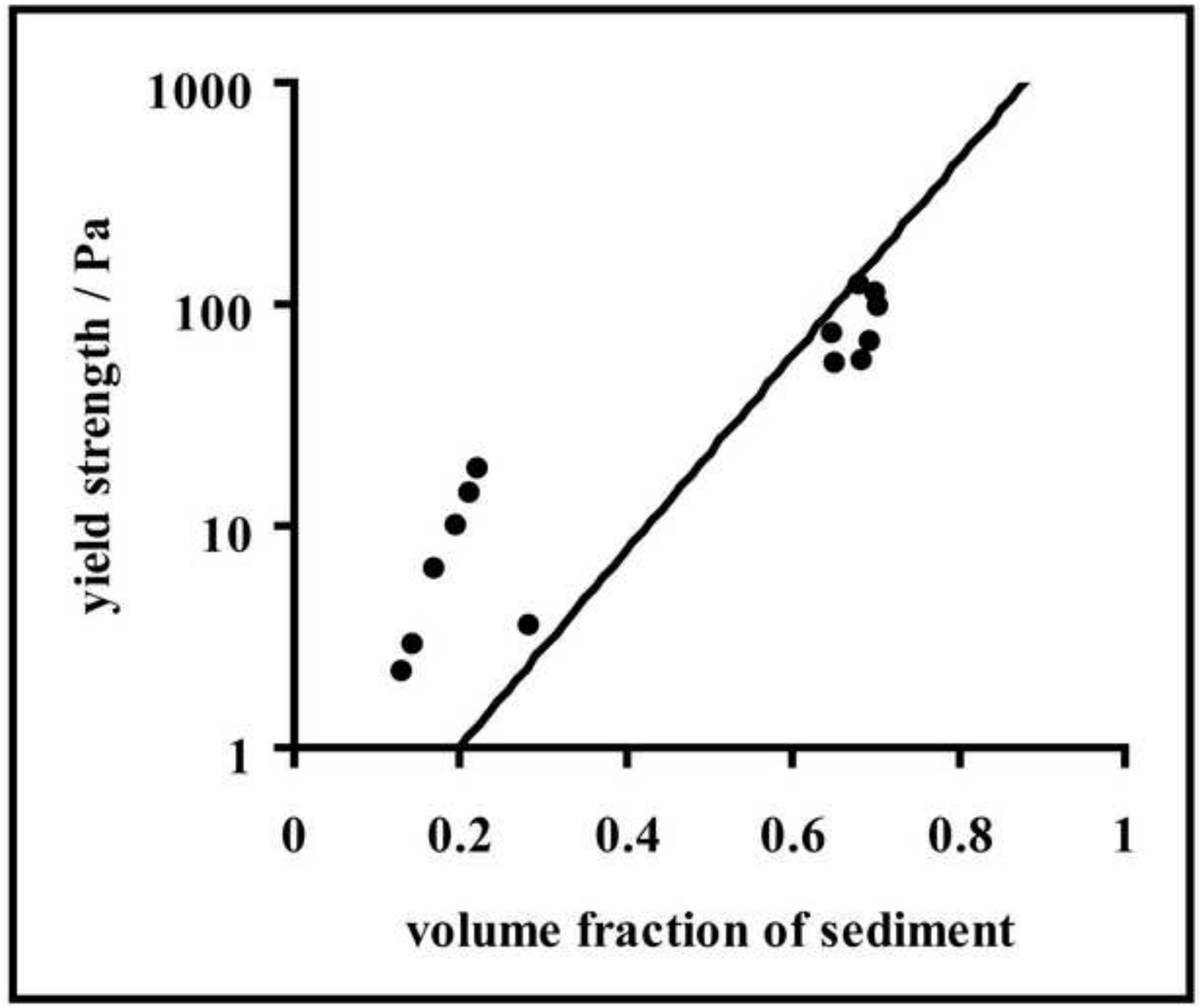




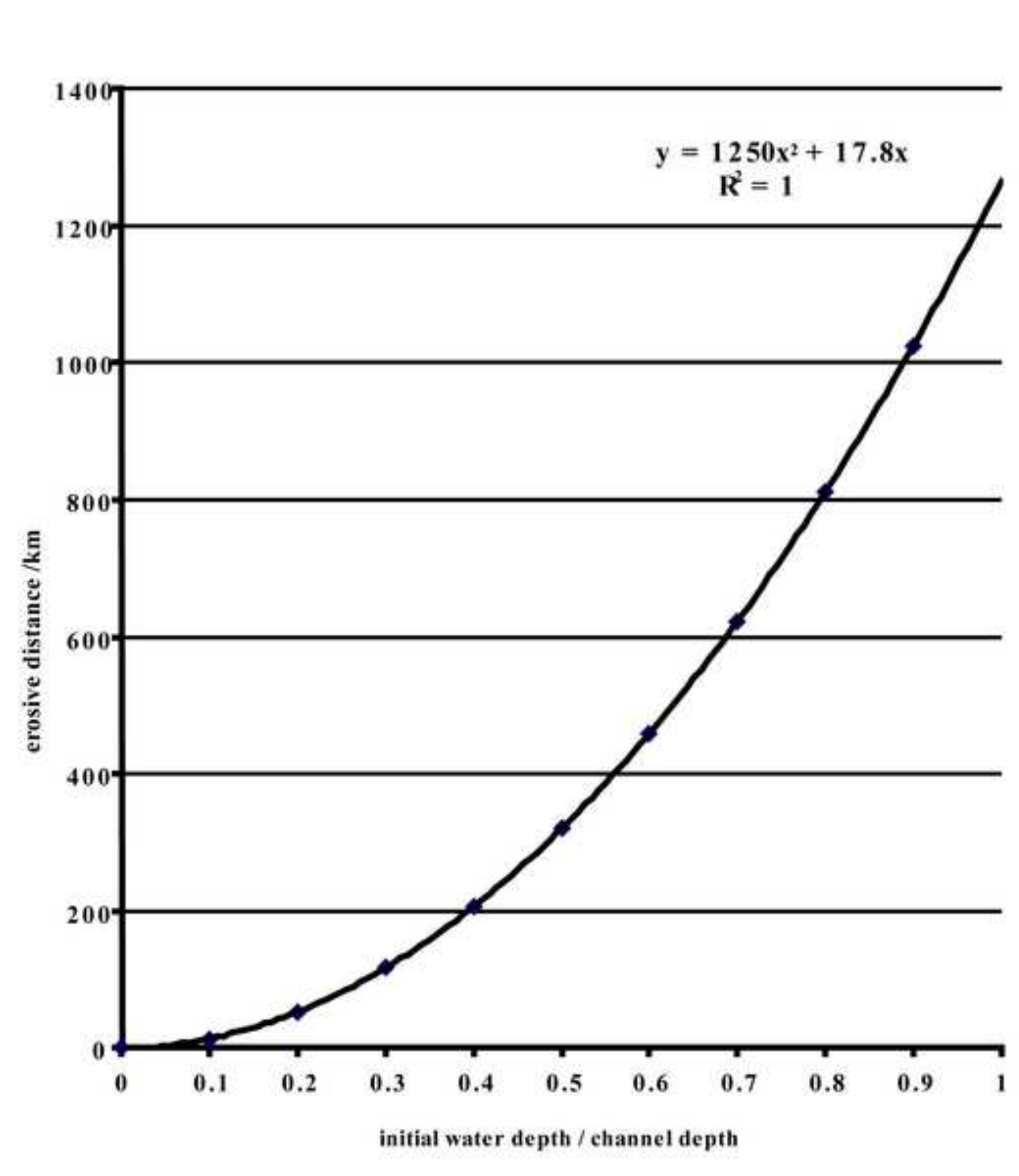

Figure 4

ACCEPTED MANUSCRIPT

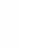

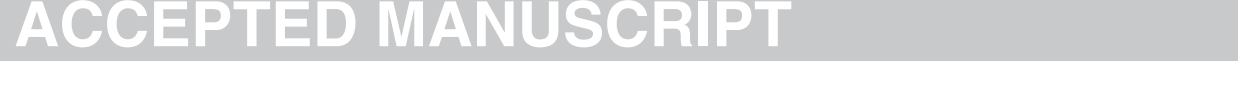

(



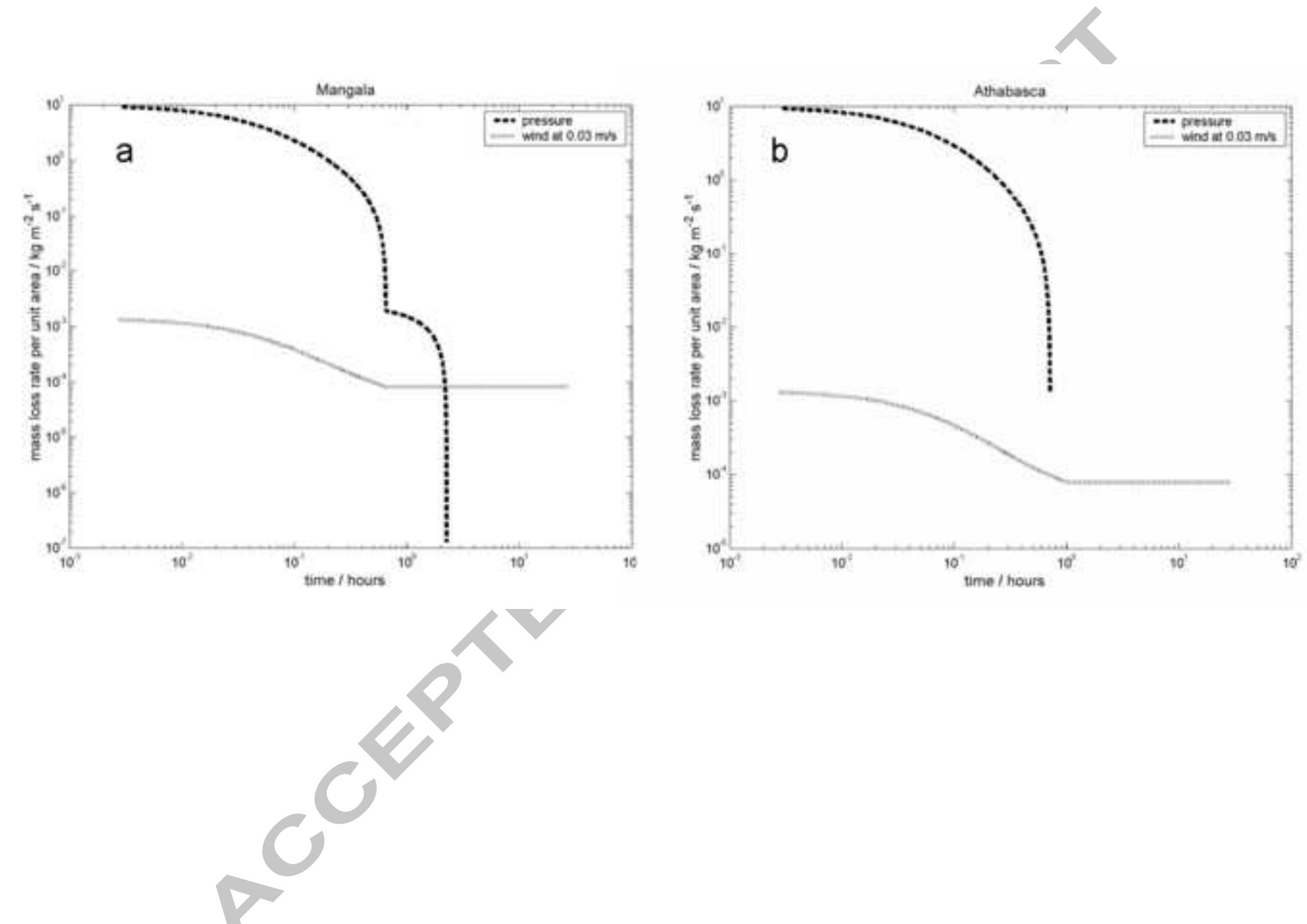 \\ ACCEPTED MANUSCRIPT}

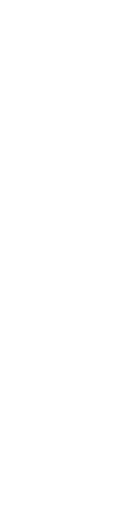

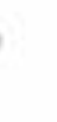
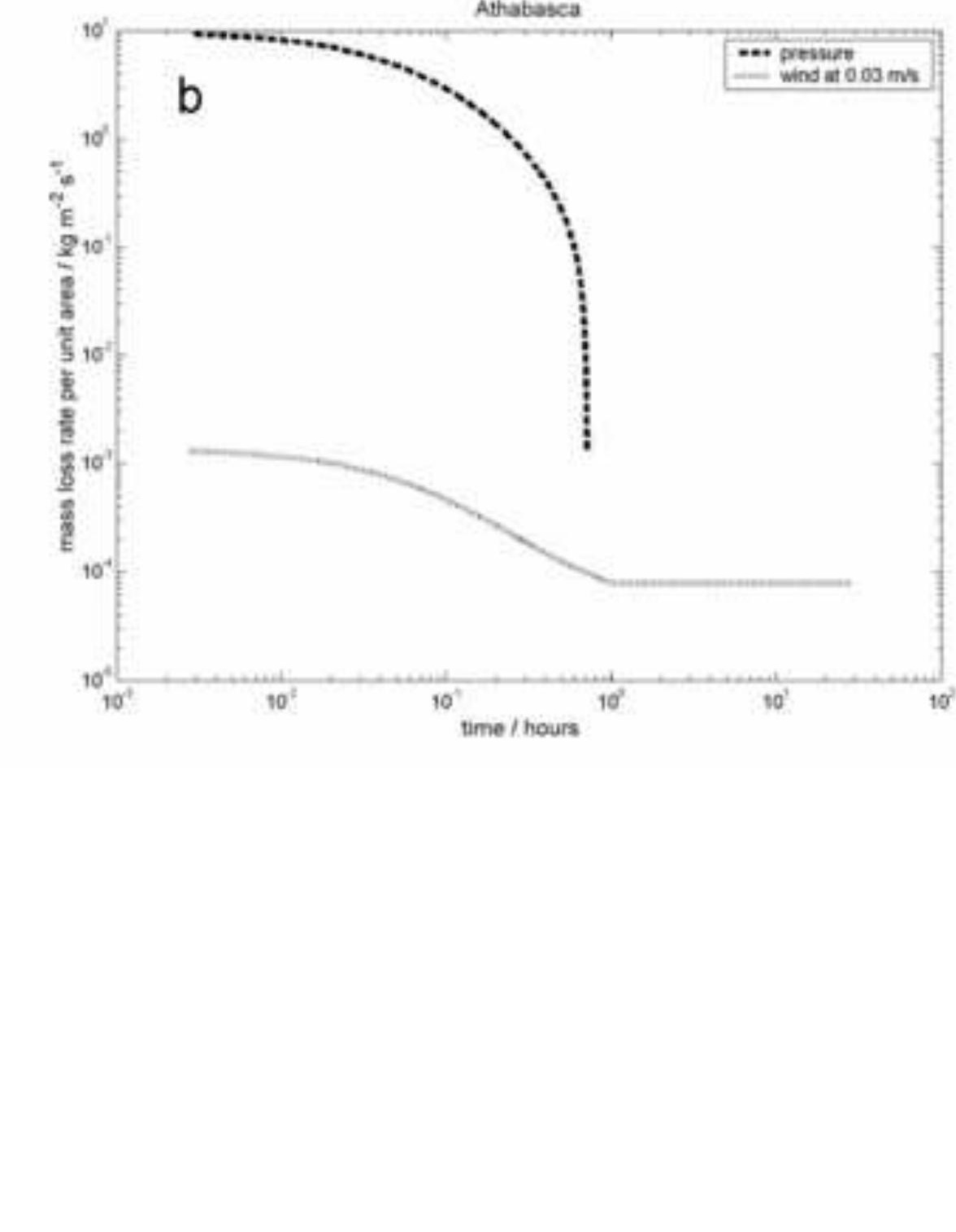

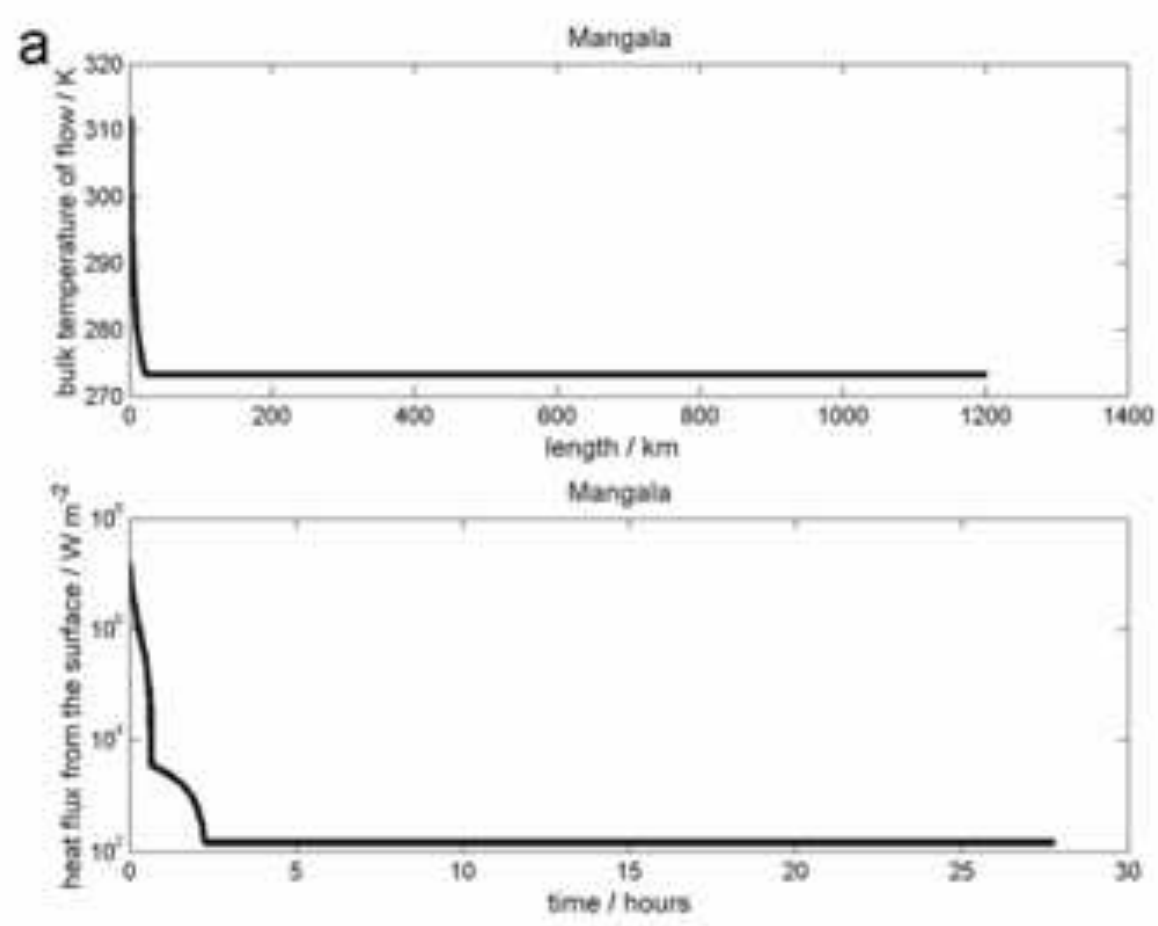

\section{Figure 6}

a time / hours
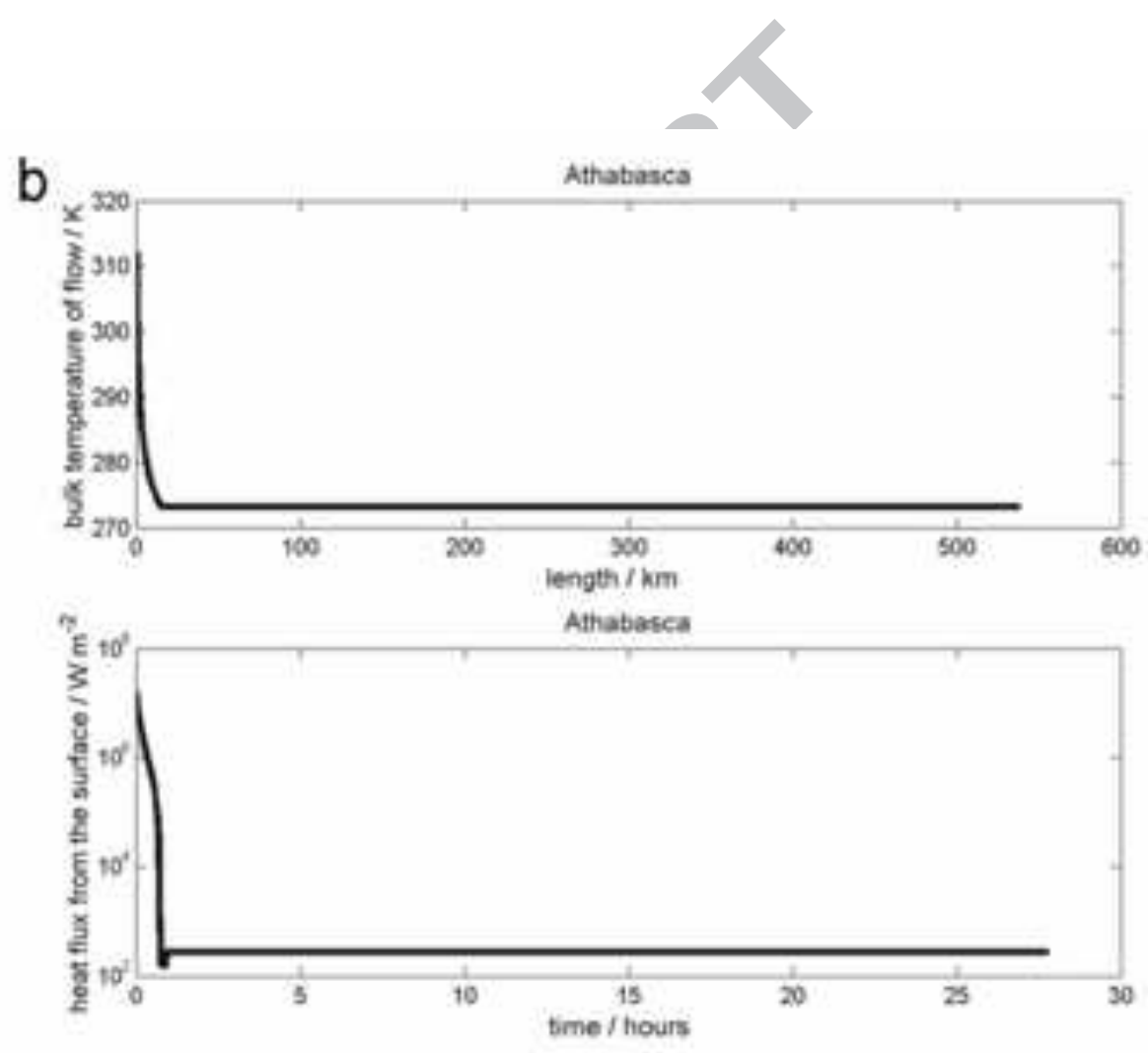

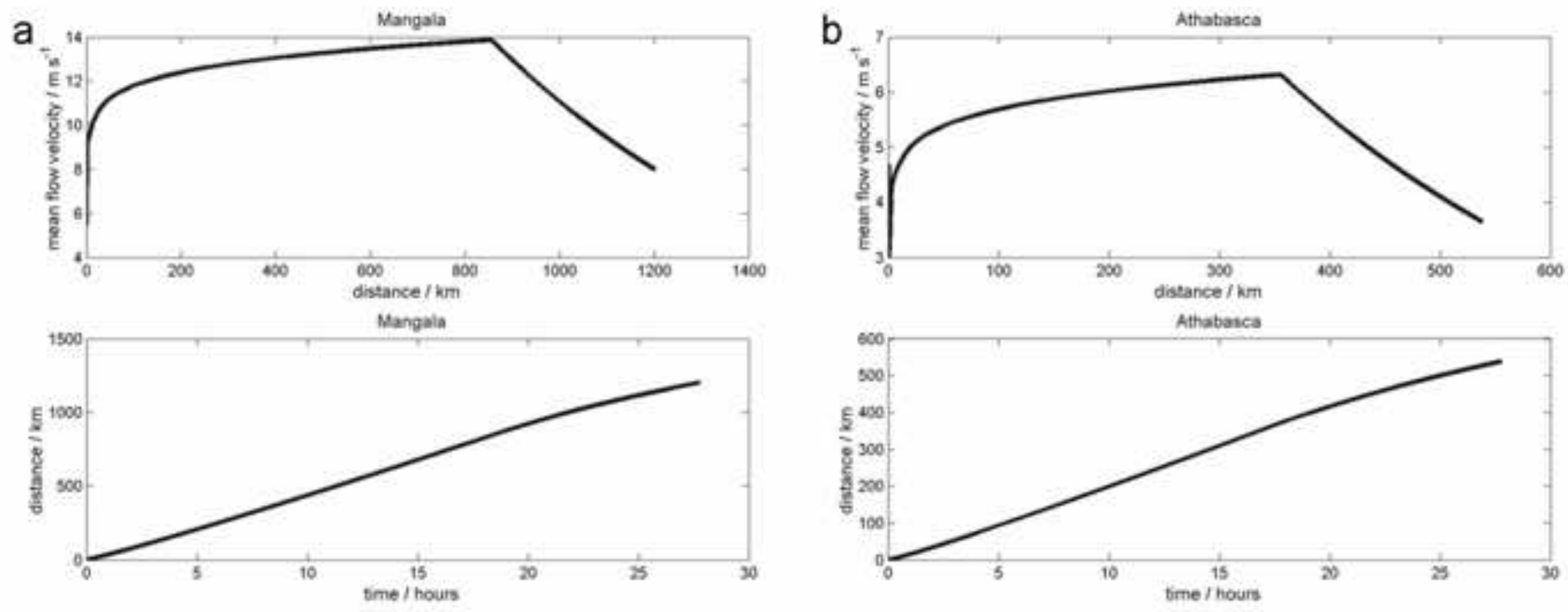

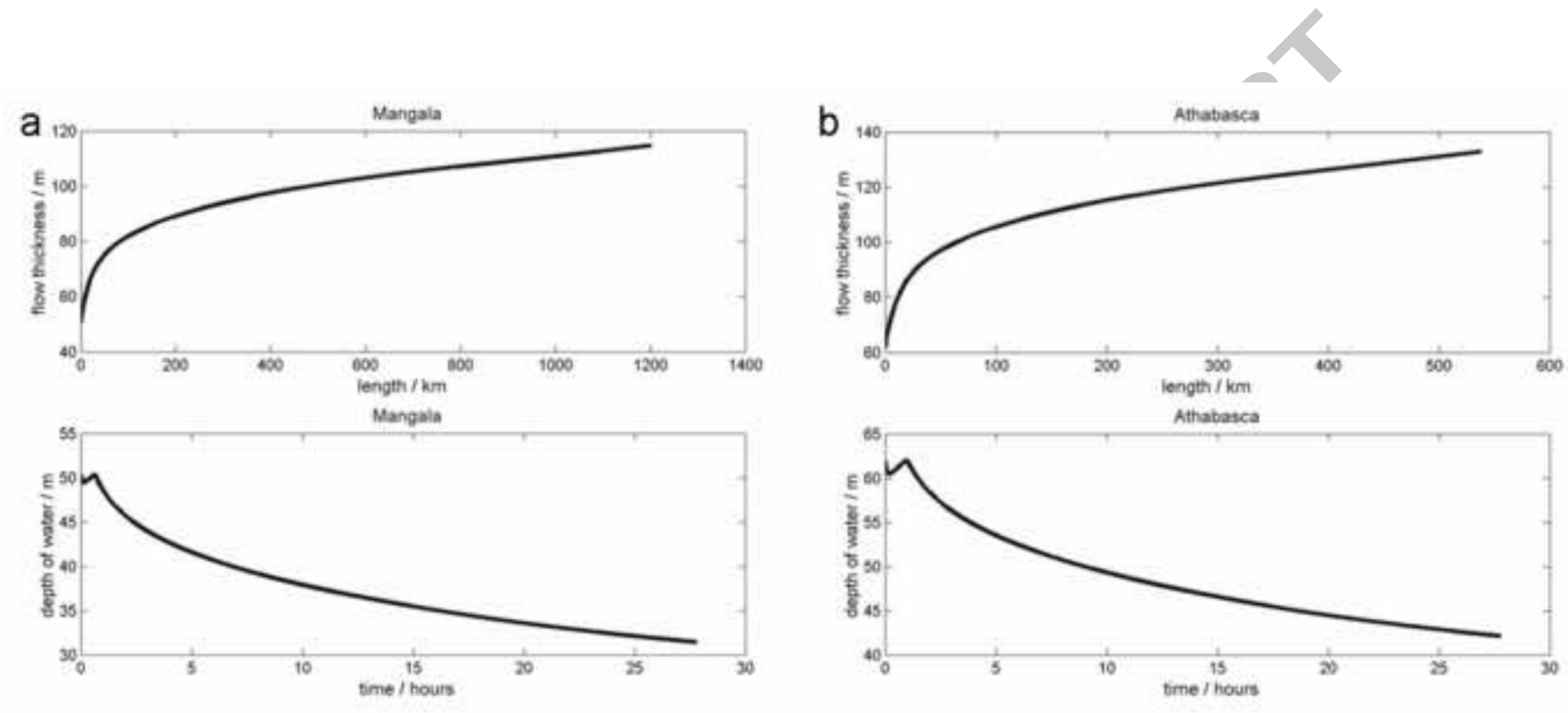

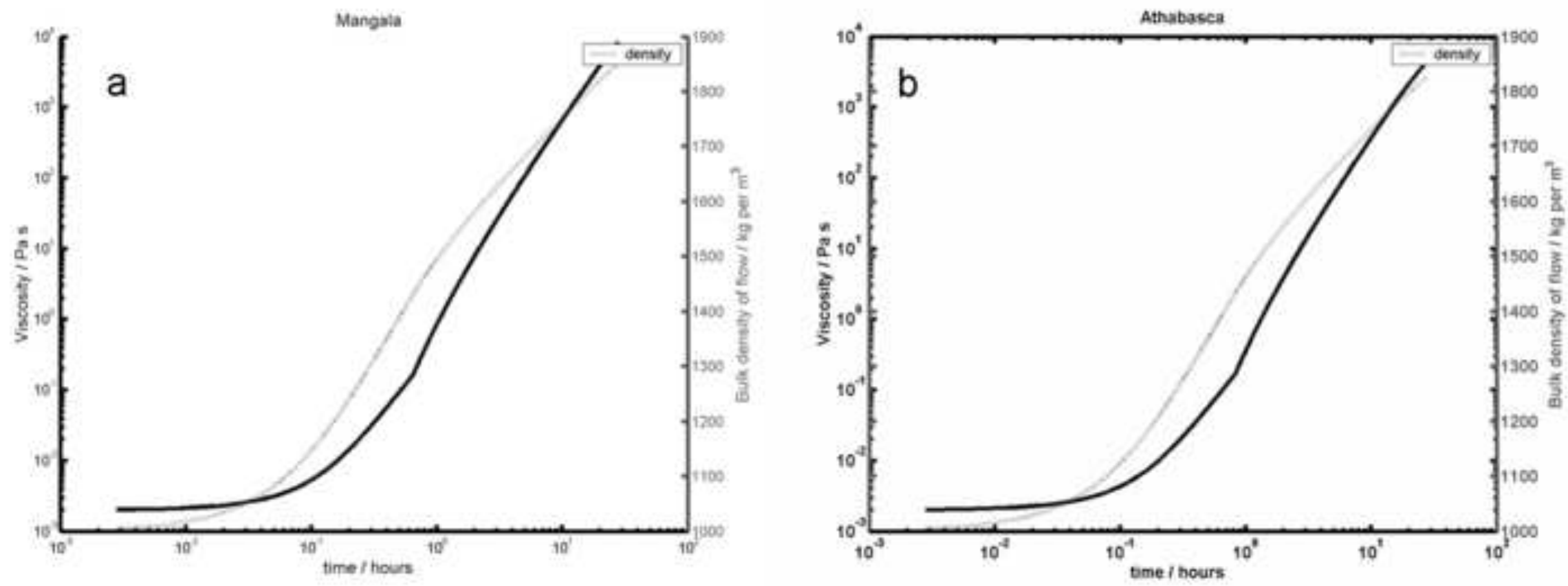

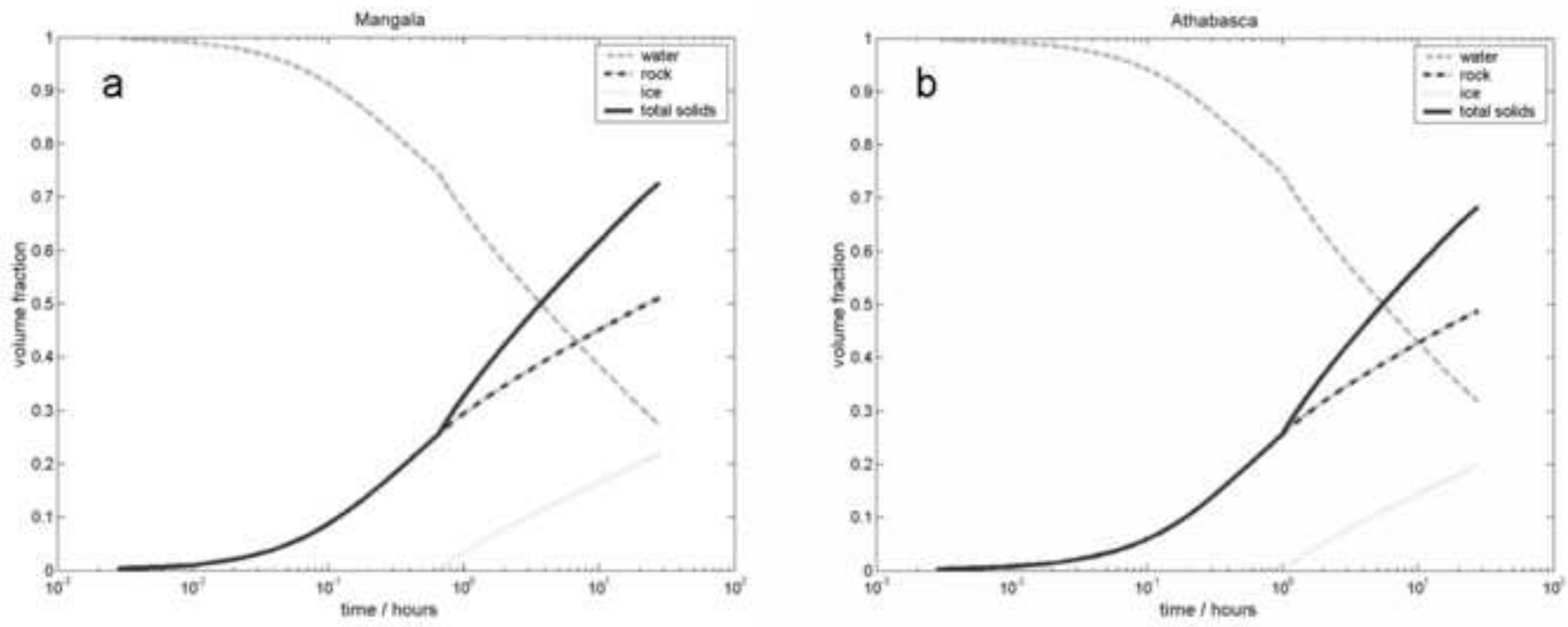

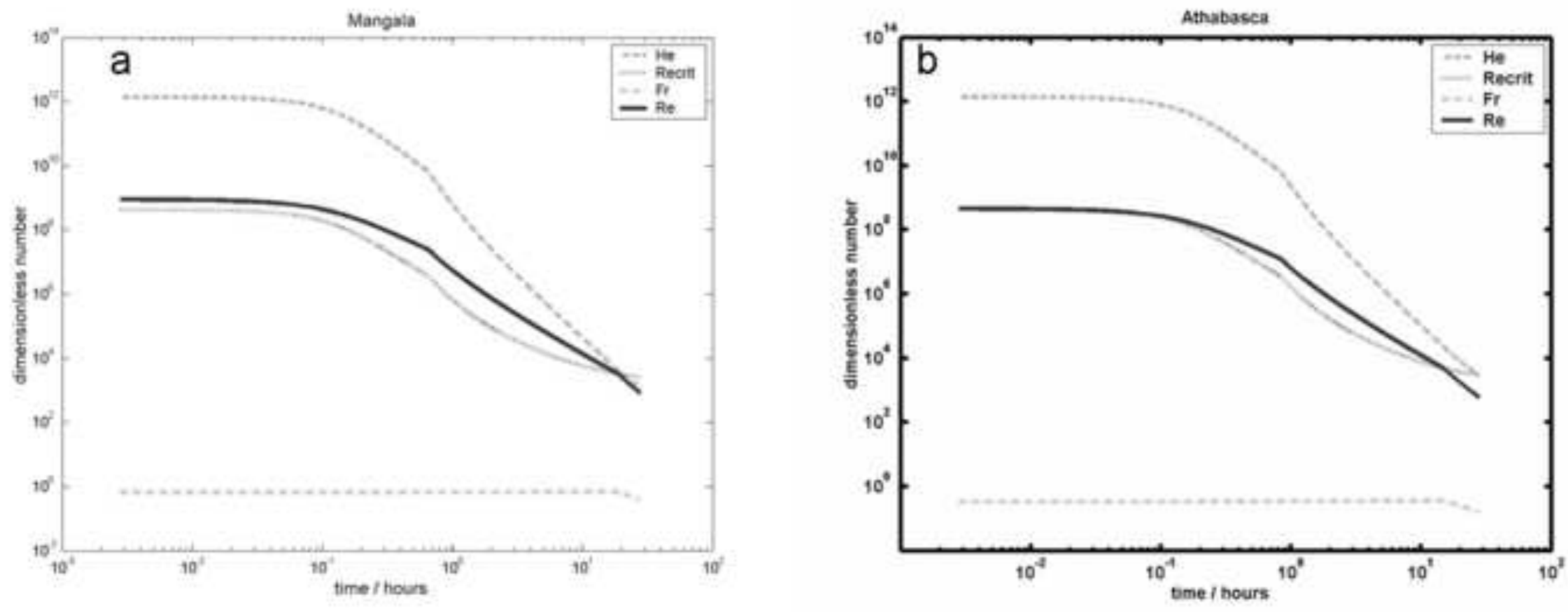

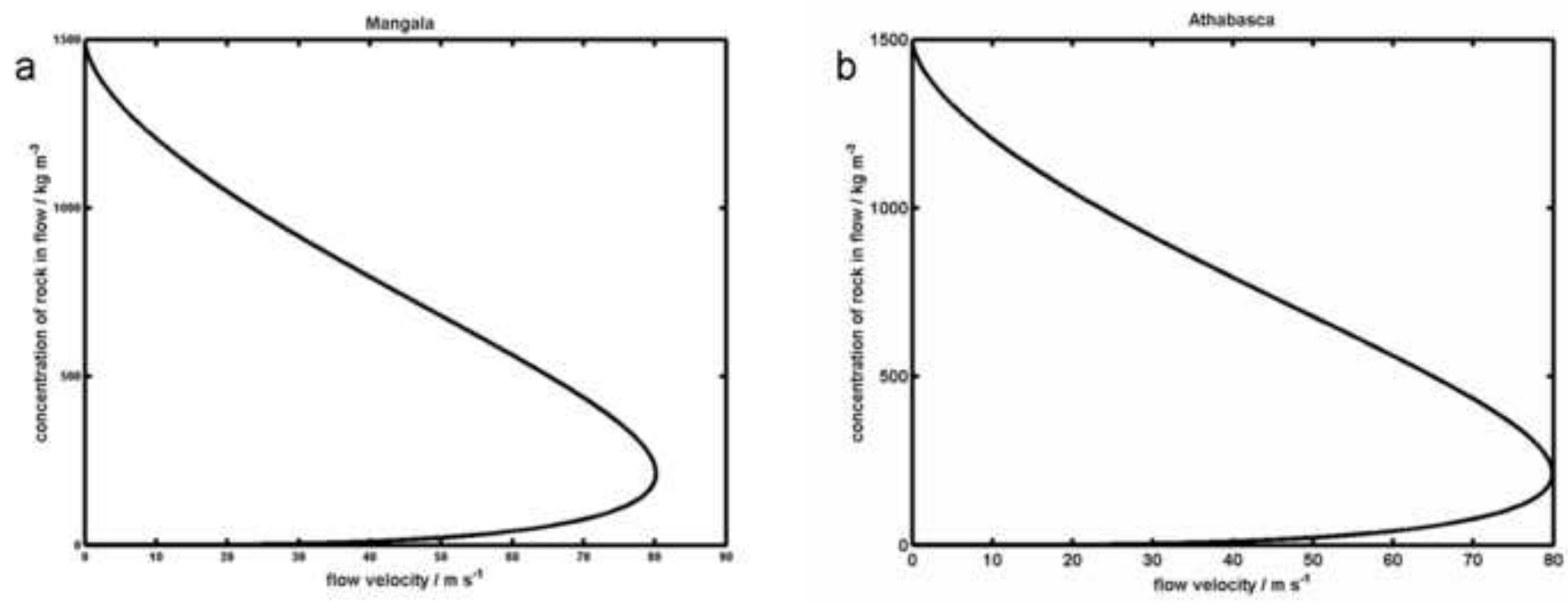

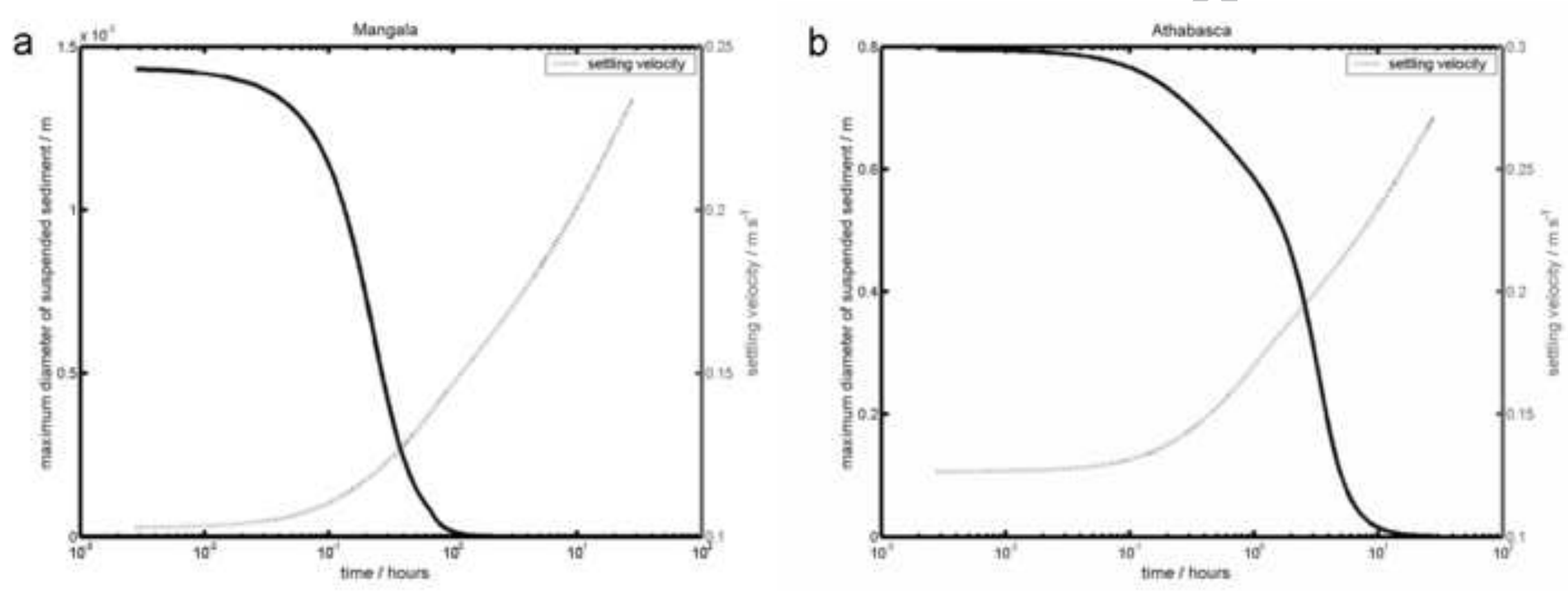

\section{Figure 13}


a

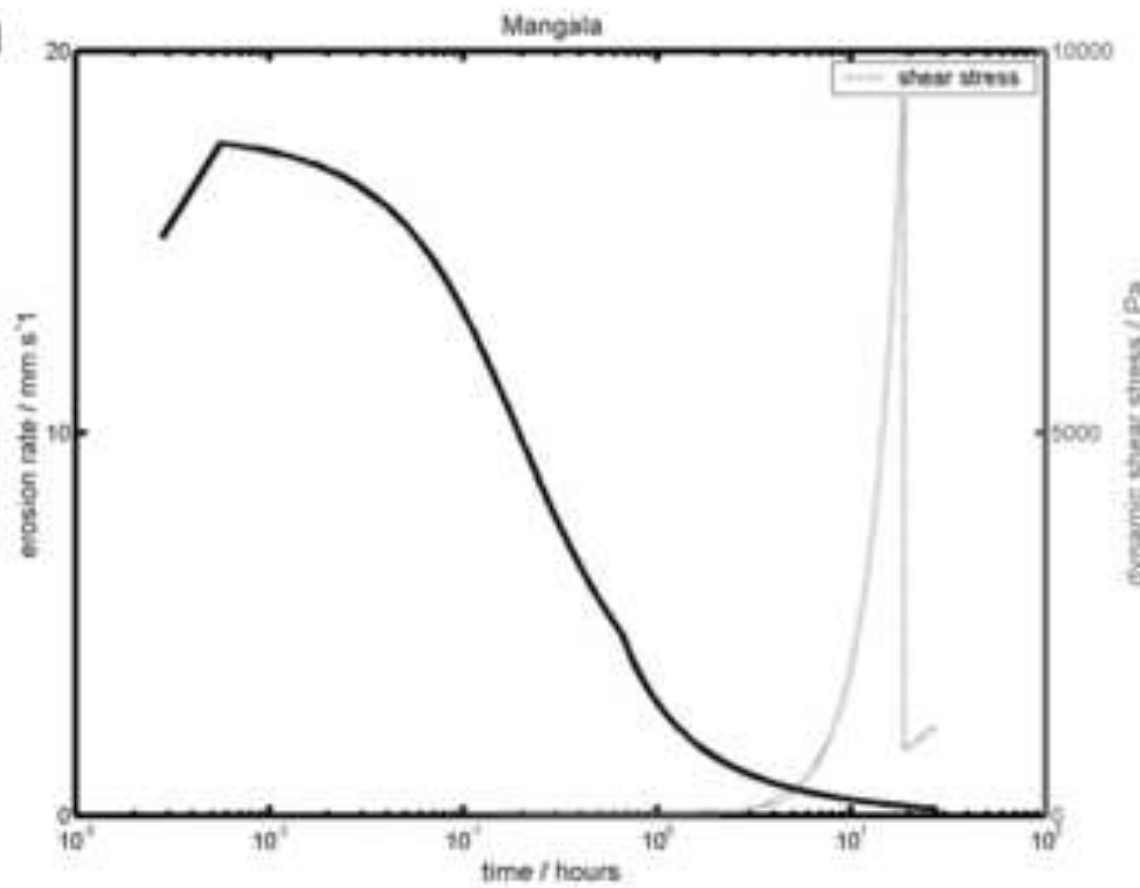

b

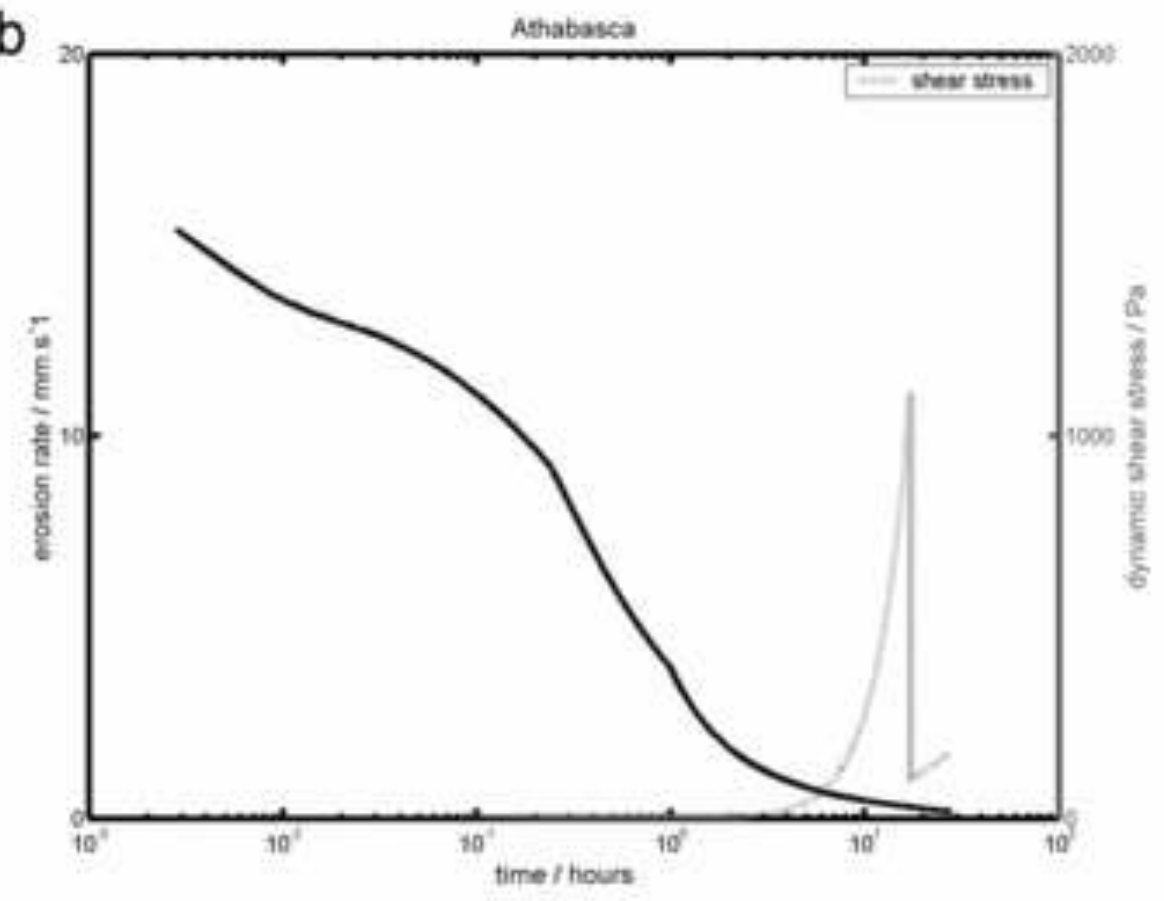




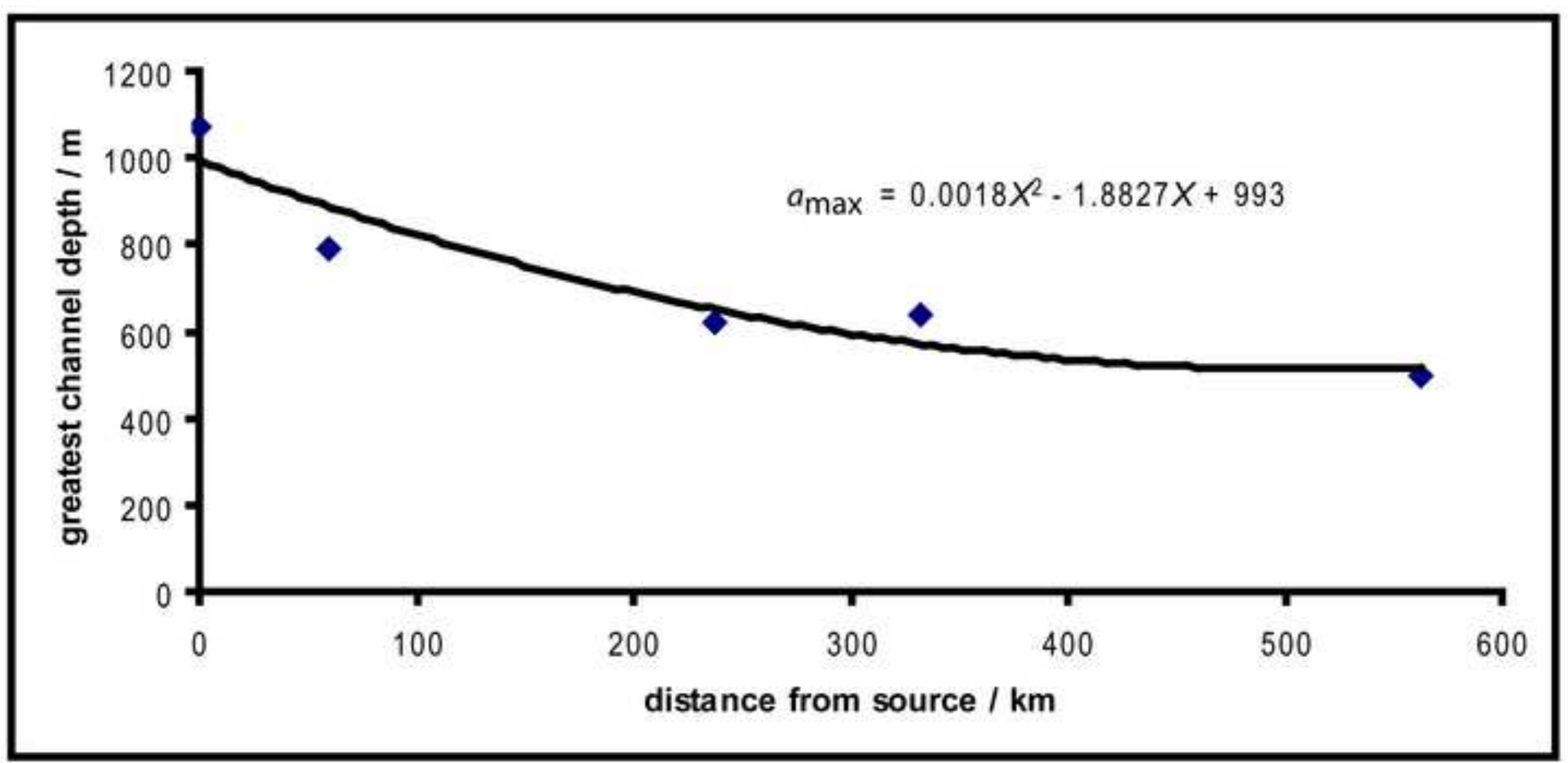


F i g 16

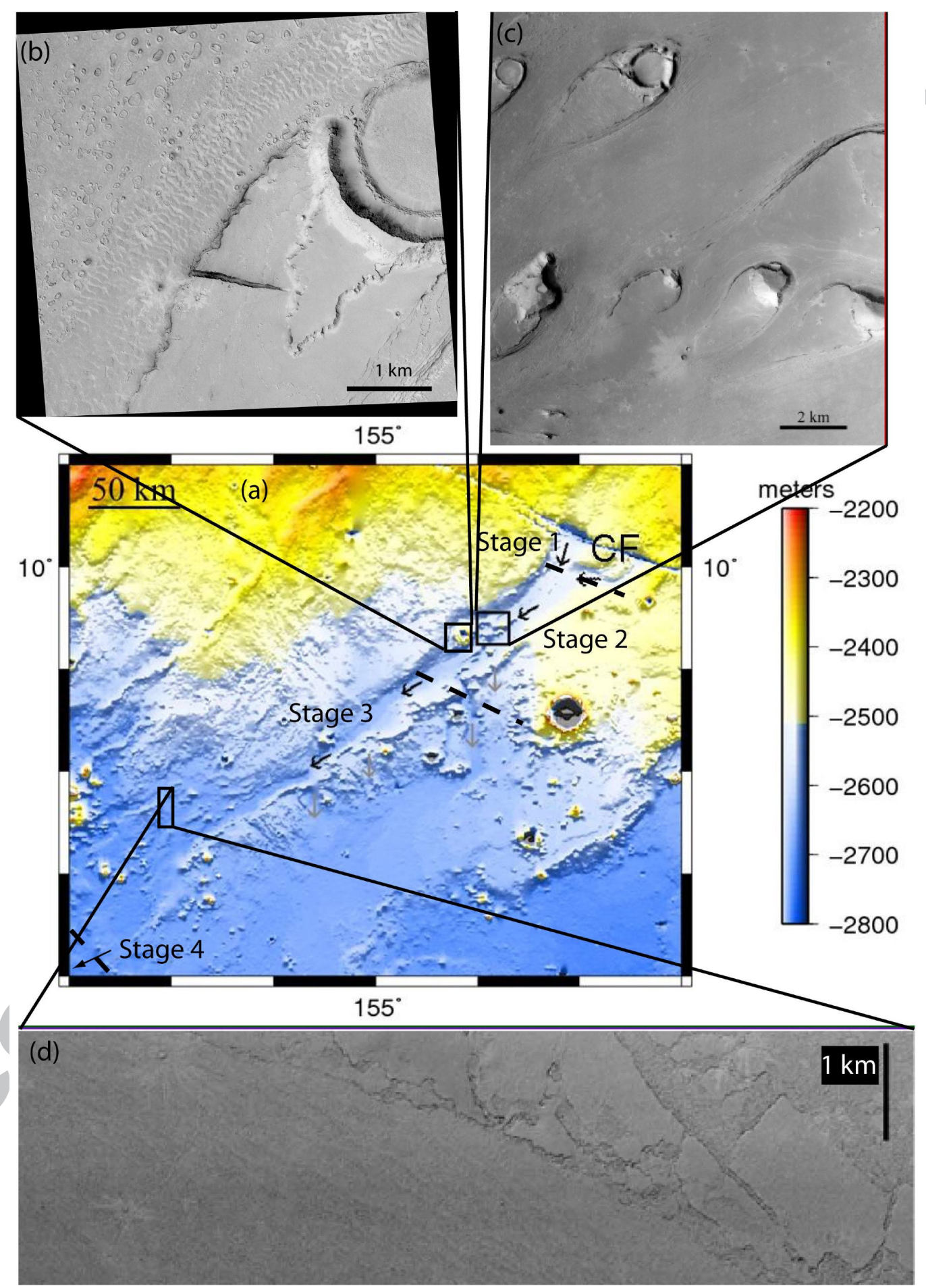




\section{Notation}

$\begin{array}{lrr}\text { Symb Definition } & \text { Units } & \text { Value if } \\ \text { ol } & & \text { constan ter type }\end{array}$

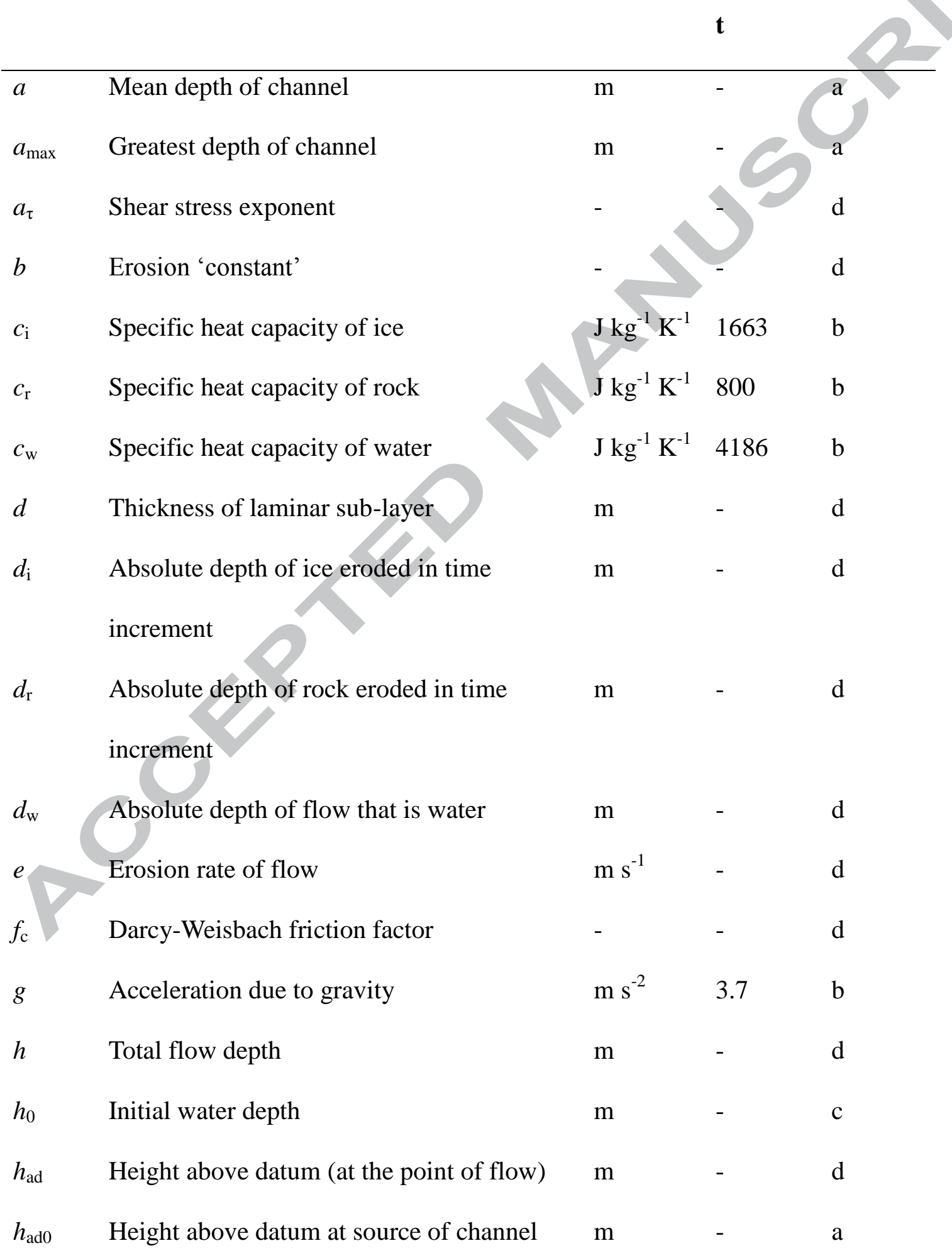




\begin{tabular}{|c|c|c|c|}
\hline$h_{\text {scale }}$ & Scale height of Mars' atmosphere & $\mathrm{m}$ & 11000 \\
\hline$i_{\mathrm{wt}}$ & $\begin{array}{l}\text { Absolute depth of flow that is melted } \\
\text { eroded ice }\end{array}$ & - & - \\
\hline$q$ & Volume fraction of cryosphere that is ice & - & 0.15 \\
\hline$r$ & Hydraulic radius of channel & $\mathrm{m}$ & - \\
\hline $\mathrm{t}$ & Time & $\mathrm{s}$ & - \\
\hline$u$ & $\begin{array}{l}\text { Flow velocity at a given depth below } \\
\text { surface of flow }\end{array}$ & $\mathrm{m} \mathrm{s}^{-1}$ & - \\
\hline $\bar{u}$ & Mean flow velocity & $\mathrm{m} \mathrm{s}^{-1}$ & \\
\hline$u_{\mathrm{c}}$ & Critical wind velocity & & - \\
\hline$u_{\mathrm{f}}$ & Frictional wind velocity & & 0.3 \\
\hline$u_{\max }$ & Maximum flow speed & $\mathrm{m}$ & - \\
\hline$u_{\mathrm{p}}$ & Physical wind velocity & $\mathrm{m} \mathrm{s}^{-1}$ & - \\
\hline$u_{\chi}$ & Wind velocity at heigh & $\mathrm{m} \mathrm{s}^{-1}$ & - \\
\hline$v_{\mathrm{r}}$ & Volume fraction of flow that is bedrock & - & - \\
\hline$z_{0}$ & Roughness length characteristic of the & $\mathrm{m}$ & 0.033 \\
\hline
\end{tabular}
surface

$D \quad$ Diffusion coefficient of water vapour $\quad \mathrm{m}^{2} \mathrm{~s}^{-1} \quad-\quad \mathrm{d}$

$D_{50} \quad$ Bed clast size for which $50 \%$ are smaller $\quad \mathrm{m} \quad$ - $\quad$ c

$D_{84} \quad$ Bed clast size for which $84 \%$ are smaller m $\quad-\quad$ c

$D_{\max } \quad$ Maximum clast size transported in $\quad \mathrm{m} \quad-\quad \mathrm{d}$ suspension

$D_{*} \quad$ Bonnefile number $\quad-\quad \mathrm{d}$

$E_{\text {free }} \quad$ Mass flux of water lost per unit area due to $\mathrm{kg} \mathrm{m}^{-2} \quad-\quad \mathrm{d}$ free convection

$E_{\text {pres }} \quad$ Mass flux of water lost per unit area due to $\mathrm{kg} \mathrm{m}^{-2} \quad-\quad \mathrm{d}$ 
$\Delta P$

$E_{\text {tot }} \quad$ Total mass flux of water lost per unit area $\mathrm{kg} \mathrm{m}^{-2} \quad-\quad \mathrm{d}$

$E_{\text {wind }} \quad$ Mass flux of water lost per unit area due to $\mathrm{kg} \mathrm{m}^{-2} \quad-\quad \mathrm{d}$ the wind

He Hedström number

$K_{\tau} \quad$ Coefficient of cavitational erosion

$L \quad$ Distance flow has travelled

$\mathrm{m}$

$L_{\mathrm{e}} \quad$ Latent heat of evaporation of water or

$\mathrm{J} \mathrm{kg}^{-1} \quad 2.5 \times 10^{6} \quad \mathrm{~b}$

sublimation of ice

$L_{\mathrm{f}} \quad$ Latent heat of fusion of ice

$\mathrm{J} \mathrm{kg}^{-1} \quad 334900 \quad \mathrm{~b}$

$M_{\mathrm{c}} \quad$ Molecular mass of $\mathrm{CO}_{2}$

$\mathrm{kg} \mathrm{kmol}^{-} \quad 44.01 \quad \mathrm{~b}$

$M_{\mathrm{w}} \quad$ Molecular mass of $\mathrm{H}_{2} \mathrm{O}$

$\mathrm{kg} \mathrm{kmol}^{-} \quad 18.02 \quad \mathrm{~b}$

1

$\begin{array}{lllll}P_{0} & \text { Atmospheric pressure at datum } & \mathrm{Pa} & 610 & \mathrm{~b}\end{array}$

$P_{\mathrm{a}} \quad$ Atmospheric pressure at surface (at flow $\quad \mathrm{Pa} \quad-\quad \mathrm{d}$ head)

$P_{\mathrm{v}} \quad$ Vapour pressure of water

$\mathrm{Pa}$

d

$P_{\mathrm{v} 0} \quad$ Vapour pressure of water at the triple point

$\mathrm{Pa} \quad 611 \quad \mathrm{~b}$

$\Delta P \quad$ Difference between $P_{\mathrm{v}}$ and $P_{\mathrm{a}}$

$\mathrm{Pa} \quad-\quad-\quad d$

Q Universal gas constant

$\mathrm{J} \mathrm{mol}^{-1} \quad 8.314 \quad \mathrm{~b}$

$\mathrm{K}^{-1}$

$Q_{\mathrm{cw}} \quad$ Heat loss flux from water by evaporation

$\mathrm{W} \mathrm{m}^{-2}$

d

$Q_{\mathrm{r}} \quad$ Heat required to warm eroded material

J $\quad-\quad$ d

$Q_{\mathrm{v}} \quad$ Viscous heat production in fluid $\quad \mathrm{W} \mathrm{m}^{-2} \quad-\quad \mathrm{d}$

$R_{\mathrm{d}} \quad$ Absolute depth of flow that is rock $\quad$ m $\quad-\quad \mathrm{d}$ 
Re Reynolds number

$R e_{\text {crit }} \quad$ Critical Reynolds number

$S_{\mathrm{t}} \quad$ Slope of channel floor

radians

a

W $\quad$ Mean width of channel

$\mathrm{m}$

a

$X \quad$ Distance from source (at flow head)

$\mathrm{m}$

d

$X_{\max } \quad$ Maximum lateral distance flow can travel $\mathrm{m}$

$\alpha \quad$ Coefficient of evaporation

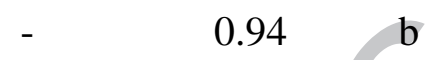

$\alpha_{c} \quad$ Coefficient of capacity

$\mathrm{kg}^{-1} \mathrm{~m}^{3}$

$\gamma_{\mathrm{m}} \quad$ Specific weight of solids in the flow

$\mathrm{kg} \mathrm{m}^{-2} \mathrm{~s}^{-}$

d

2

$\varepsilon \quad$ Coefficient of proportionality for thermal erosion

$\eta \quad$ Characteristic velocity of the diffusion $\quad \mathrm{m} \mathrm{s}^{-1} \quad-\quad \mathrm{d}$ process

$\theta_{\mathrm{a}} \quad$ Surface temperature of Martian atmosphere $\mathrm{K}$ $210 \quad b$

$\theta_{c} \quad$ Surface temperature of Martian cryosphere K $210 \quad b$

$\theta_{\mathrm{eq}} \quad$ Temperature of the water after losing heat $\quad \mathrm{K}$

K $\quad-\quad d$
by erosion

$\theta_{\mathrm{f}} \quad$ Freezing point temperature of water

K

$273.15 \quad b$

$\theta_{\mathrm{w}} \quad$ Temperature of water

K

d

$\theta_{\mathrm{wv}} \quad$ Temperature of water vapour

K

d

$\Delta \theta_{\mathrm{w}} \quad$ Change in water temperature due to erosion $\mathrm{K}$

K $\quad-\quad$ d

$1 \quad$ Coefficient of velocity profile

$0.3293 \quad b$

$\kappa_{\mathrm{vk}} \quad$ Von Karman constant

$0.40 \quad b$

$\mu \quad$ Dynamical viscosity of flow

Pa s

d

$\mu_{0}$

Dynamical viscosity of water at the triple

Pa s

$0.0015 \quad b$ 
point

$\mu_{\mathrm{a}} \quad$ Dynamical viscosity of Mars' atmosphere $\quad$ Pa s $\quad-$

$\xi \quad$ Kinematic viscosity of atmosphere $\quad \mathrm{m}^{2} \mathrm{~s}^{-1} \quad-\quad \mathrm{d}$

$\xi_{\mathrm{f}} \quad$ Kinematic viscosity of flow $\quad \mathrm{m}^{2} \mathrm{~s}^{-1} \quad-\quad \mathrm{d}$

$\rho \quad$ Total density of the atmosphere at the $\quad \mathrm{kg} \mathrm{m}^{-3} \quad-\quad \mathrm{d}$

surface (water + carbon dioxide)

$\rho_{\mathrm{a}} \quad$ Density of the atmosphere $\left(\mathrm{CO}_{2}\right)$ without $\mathrm{kg} \mathrm{m}^{-3} \quad-\quad \mathrm{d}$ water

$\rho_{\mathrm{b}} \quad$ Bulk density of hyper-concentrated flow $\mathrm{kg} \mathrm{m}^{-3}-\mathrm{d}$

$\rho_{\mathrm{i}} \quad$ Density of ice $\quad \mathrm{kg} \mathrm{m}^{-3}=914 \quad \mathrm{~b}$

$\rho_{\mathrm{r}} \quad$ Density of rock (basalt) $\quad \mathrm{kg} \mathrm{m}^{-3} \quad 2700 \quad \mathrm{~b}$

$\rho_{\mathrm{s}} \quad$ Average density of solids in flow $\quad \mathrm{kg} \mathrm{m}^{-3} \quad-\quad \mathrm{d}$

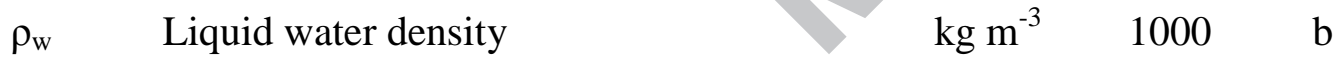

$\rho_{\mathrm{sv}} \quad$ Saturation density of water vapour at the $\mathrm{kg} \mathrm{m}^{-3} \quad-\quad \mathrm{d}$ temperature of the frost

$\Delta \rho \quad$ Difference between the density of the $\mathrm{kg} \mathrm{m}^{-3} \quad-\quad \mathrm{d}$ ambient gas (just carbon dioxide) and that of the gas at the surface (water + carbon dioxide)

$\varsigma \quad$ Fraction of flow depth that is ice formed by freezing due to erosion

$\sigma_{\mathrm{y}} \quad$ Yield strength of the flow $\mathrm{Pa} \quad-\quad \mathrm{d}$

$\tau_{0} \quad$ Dynamic shear stress

$\mathrm{Pa}$ d

$v \quad$ Coefficient of velocity profile $\quad-\quad 0.6707$

$\varphi \quad$ Total solids volume fraction $\quad-\quad-\quad$ d

$\varphi_{\max } \quad$ Capacity of flow (Maximum possible $\quad-\quad+\quad-\quad d$ 
volume fraction of solids)

$\varphi_{\text {sub }} \quad$ Concentration at maximum flow speed $\quad-\quad$ - $\quad$ d

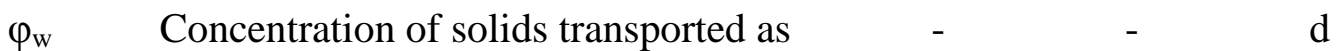

washload

$\chi \quad$ Height above surface of flow at which the $\mathrm{m} \quad-\quad \mathrm{d}$ atmosphere is dry

$\omega \quad$ Settling velocity

$\mathrm{m} \mathrm{s}^{-1}$

d 
Table 1. Summary of gross channel characteristics and best-fit model results after application to Mangala and Athabasca Valles.

\begin{tabular}{|c|c|c|}
\hline Parameter & Mangala & Athabasca \\
\hline Mean channel width / km & 35 & 20 \\
\hline Mean channel depth / m & 60 & 100 \\
\hline Observed channel length / km & 850 & 350 \\
\hline Mean channel floor slope & 0.0005 & 0.0003 \\
\hline Height of source above datum / $\mathrm{m}$ & 0 & -2400 \\
\hline Best-fit initial water depth / $\mathrm{m}$ & 50 & 62 \\
\hline Best-fit $D_{50} / \mathrm{m}$ & 0.0014 & 0.1 \\
\hline Best-fit $D_{84} / \mathrm{m}$ & 0.0017 & 0.6 \\
\hline Transit time ${ }^{a} /$ hours & 18.5 & 17 \\
\hline Mean bulk density of flow / $\mathrm{kg} \mathrm{m}^{-3}$ & 1750 & 1710 \\
\hline Mean bulk viscosity of flow /F & 2530 & 930 \\
\hline Flow thickness / m & & $62-133$ \\
\hline Water depth / m & $31-50$ & $42-62$ \\
\hline Mean flow velocity $/ \mathrm{m} \mathrm{s}^{-1}$ & 12 & 5.4 \\
\hline Mean erosion rate $/ \mathrm{mm} \mathrm{s}^{-1}$ & 0.69 & 0.76 \\
\hline Stage 1 duration / hrs. & 0.65 (39 minutes) & 1 \\
\hline Stage 2 duration / hrs. & N/A & 4 \\
\hline Stage 3 duration / hrs. & 17.9 & 12 \\
\hline Solids fraction ${ }^{\mathrm{b}}$ & 0.69 & 0.63 \\
\hline Estimate of flow duration / hrs. & 24 & 37 \\
\hline \multicolumn{3}{|c|}{${ }^{\mathrm{a}}$ The transit time is the time taken for a parcel of the flow to flow from the source region to the } \\
\hline
\end{tabular}

